\title{
Motivations for Pursuing Radical Life Extension
}

\author{
By \\ Lucinda April Campbell
}

\begin{abstract}
A thesis
submitted to the Victoria University of Wellington in fulfilment of the requirements for the degree of

Master of Arts

in Philosophy
\end{abstract}

Victoria University of Wellington

2019 


\begin{abstract}
In bio-ethics, the potential practical and ethical implications of radical life extension are being seriously debated. However, the role of motivation in relation to dramatically increasing the human life span has been largely overlooked. I propose that motivation is a crucial aspect to consider within the radical life extension discourse by conjecturing about why it might appeal and the possible ways it could impact outcomes where it is successfully developed and implemented. I do not thereby present an argument that supports or opposes radical life extension technology. This is ultimately a speculative piece. In exploring the relationship between motivation and radical life extension, I present a conceptual framework called the Thanatophobic and Romantic Motivational Spectrum (TRM Spectrum) designed to assist deeper examination on the subject. It captures what I suggest are two key motivators related to life and death, that is, the fear of death (Thanatophobia) and the "love" of life (Romanticism). The motivational spectrum is then applied to the death penalty versus life imprisonment, and euthanasia and suicide debates to demonstrate how it can be used for analysis of ethical issues in relation to the potential introduction of radical life extension technology.
\end{abstract}




\section{ACKNOWLEDGEMENTS}

This journey began as an essay and would not have been developed further without a push from my supervisor Nick Agar. Thank you for the feedback and insightful philosophical advice you gave me as I progressed through. It has been an invaluable experience. I have also been lucky enough to garner help from my friend and fellow student Santi Quartermaine-Bragg. Thanks for taking time out of your busy schedule to critique my work.

To Dad - for all the biscuits, rides, support and being sparkly, and my sister Anna for moral support and understanding when I couldn't help you at The Oatery. Also, a big thank you to Chris Kilbride. Your support kept me sane(r) and I thoroughly enjoyed the cous-cous/chicken dinners you would bring to uni when I stayed late.

And, Mum. Your support and belief in my work has been beyond words. Thank you for providing helpful feedback at various stages of this thesis as well as the conversations in general. I am very lucky. This thesis is dedicated to you. 


\section{CONTENTS}

Introduction------------------------------------------------------------------------------------------------- 8

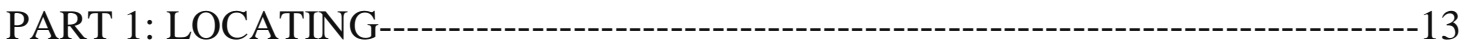

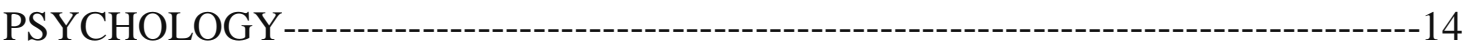

1.1: The fear of death------------------------------------------------------------------------------14

1.2: Positive psychology and existential positive psychology------------------------------16

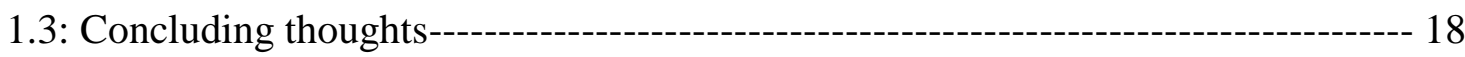

THE PHILOSOPHICAL DEBATE-----------------------------------------------------------19

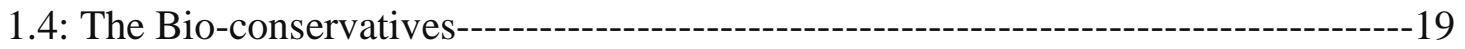

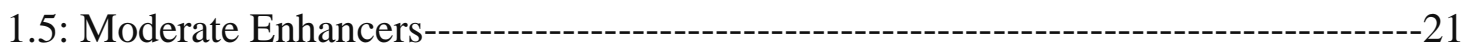

1.6: The Transhumanists----------------------------------------------------------------------------22

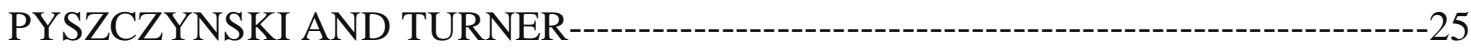

1.7: Thomas Pyszczynski: TMT and negative reactions to radical life extension-------25

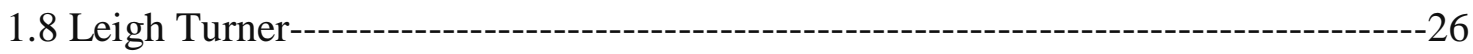

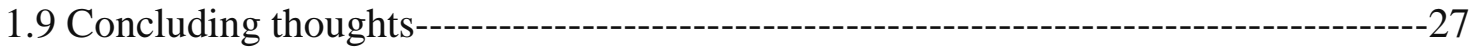

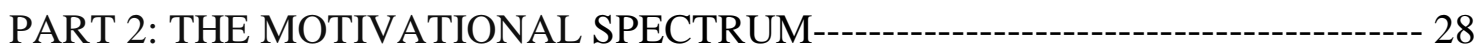

INDIVIDUAL THANATOPHOBIC AND ROMANTIC MOTIVATION---------------28

2.1: Are you afraid of the dark? Our motives for extended life----------------------------- 28

2.2: 'I have more living to do' versus 'I don't want to die'-------------------------------30

EMPATHETIC AND SOCIETAL MOTIVATIONS----------------------------------------33

2.3: Motivation beyond the individual----------------------------------------------------------33

2.4: Microsystem to the Chronosystem--------------------------------------------------------34

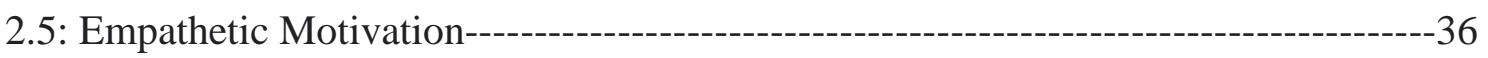

2.6: Societal Motivation--------------------------------------------------------------------------38

2.7: Concluding thoughts: Individual, Empathetic and Societal Motivation---------------41

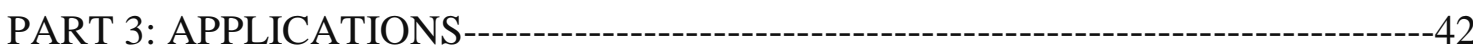

3.1: THE DEATH PENALTY VS. LIFE IMPRISONMENT---------------------------42

3.11: Some context: the death penalty, life imprisonment and notions of deterrence---43

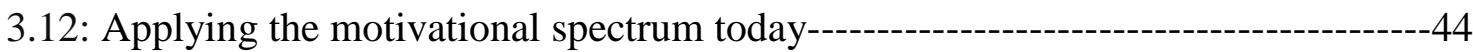

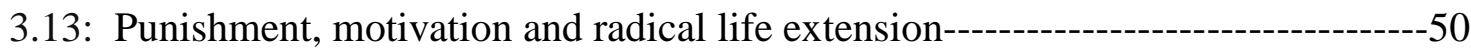

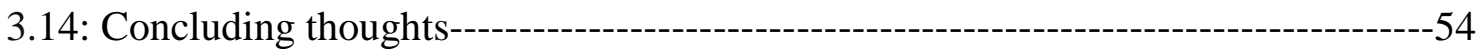


3.2: EUTHANASIA AND SUICIDE $-55$

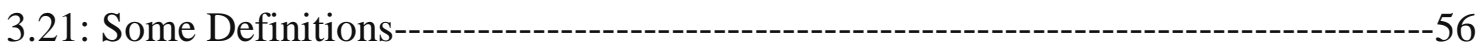

3.22: The current euthanasia and suicide debate----------------------------------------------56

3.23: Radical life extension enters the picture-------------------------------------------------60

3.24: Moral or immoral suicide at a societal level----------------------------------------------63

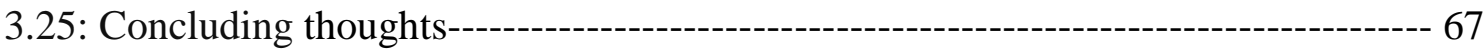

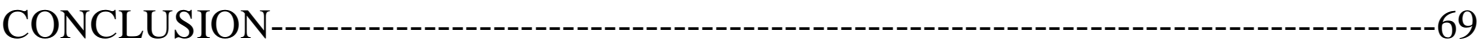

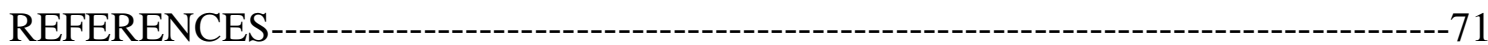


"The fear of death never left me; I couldn't get used to the thought; I would still sometimes shake and weep with terror. By contrast, the fact of existence here and now sometimes took on a glorious splendour.”

Simone de Beauvoir, Memoirs of a Dutiful Daughter (268) 


\section{INTRODUCTION}

Developments in bio-technology are pushing the possibility of youthful longevity beyond the bounds of science fiction into potential reality. In this thesis, I explore the role of motivation in relation to the use of radical life extension technology and why it is a crucial consideration within the life extension debate. I propose that understanding our relationship to life and death is key to understanding why radically extending the human lifespan may appeal to many individuals. It is likely that motivation will not only affect the decision and act of using radical life extension technology, but also the way in which it is treated as a technology. At first glance, it is easy to think the issue of life extension is clear cut in terms of 'death bad, life good', or that an individual who opts for such technology obviously wants to live longer - without any further analysis.

I contend that our motivations to live longer are complex and require deeper examination than has previously been undertaken. In making this examination, a framework to aid analysis is presented, using what I believe are two fundamental factors likely to motivate human-use of life extension technology - Thanatophobia, the fear of death, and Romanticism, an appreciation or "love" of life. These concepts sit at either end of a Spectrum designed to capture the nuances of motivation relating to the use of radical life extension technology. I pose that Thanatophobic and Romantic motivations stand as separate concepts - although both can result in the same outcome of opting for life extension, they do so in very different ways. That is not to say these motivations are mutually exclusive - it is possible for an individual to be motivated by both at the same time and to varying degrees.

This thesis is ultimately an exploratory piece. I conjecture how Thanatophobic and Romantic motivations are likely to play a crucial role in the pursuit and use of life extension, but I am not asserting that they are the only motivating factors related to using radical life extension technologies. The analysis presented here is intended as a starting point, to facilitate further discussion about the complex role of motivation in the radical life extension debate. This is especially pertinent because very little research and analysis has been done on this subject. The Thanatophobic and Romantic Motivational Spectrum (TRM Spectrum) is, therefore, intended as a framework to help conceptualise the way motivation might influence the use of radical life extension. 
It is worth noting that "Thanatophobia" is an existing word that literally refers to a fear of death (“Thanato-”). The term "Romantic” as a motivation (defined below), has conversely been adapted to suit the purposes of this thesis. With this in mind, I have defined Thanatophobic and Romantic motivations as follows:

- Thanatophobic motivation: The motivation to extend life due to a fear of death. This can include a conscious or unconscious anxiety related to the unknown of what occurs at death and the prospect of facing it alone.

- Romantic motivation: The motivation to extend life due to an enjoyment, or "love" of life. Romantic reasons might include pursuing various hobbies and/or careers, important relationships, a sense of importance regarding one's existence and the various material pleasures life has to offer. Though the term "love” of life denotes something positive, it does not necessarily have to be. A tyrannical dictator, for instance, might radically extend their life because they want to maintain their power for as long as possible.

I now briefly outline how the term "motivation" is used in this thesis to provide context for the reader before discussing the TRM Spectrum and radical life extension. It is a complex topic so only a limited description can be provided. The term "motivation" denotes a mental state - comprising aspects such as desire, belief, thought or emotion - that may influence, or compel, an agent's reason to perform an action (Lai 5). For example, Jordan might be motivated to drink a beer at his friend's barbeque because he enjoys the taste of it and believes it will increase his likelihood of having a good time. Motivation may also come in degrees. By this, I mean it is possible for different people to have the same motivation but to experience it at varying intensities. Although Leanne and Jordan are motivated to drink beer at the barbeque, Jordan is more motivated to drink it than Leanne because he derives greater pleasure from beer drinking. Equally “degrees” of motivation can change temporally and Jordan may have a stronger motivation to drink beer at this barbeque than he did at the last one he attended. I propose that it is possible to apply similar motivational prompts to the TRM Spectrum in relation to radical life extension. For example, while Diana and Jac may be Romantically motivated to radically extend their lives, Diana's “love” of life and motivation for radical life extension may initially be stronger than Jac's. However, over time it is 
possible that Diana's Romantically inclined motivations for extended life will decrease while Jac's increase because of the enjoyment she is deriving from the new and unforeseen opportunities of her extended life.

Motivation linked to the likes of action influencing desires, beliefs, thoughts or emotions may also be experienced at both conscious and unconscious levels. At a 'conscious' level an individual is aware of what is directly influencing their actions (Bargh 32; Forgas et al. 8). For example, Chris is aware that his decision to buy a pet cat rather than a dog is motivated by the fear of dogs he developed after being bitten by one as a child. Conversely, unconscious motivation is where an individual is unaware of some fundamental deep-seated influence (Bargh 32, Forgas et al.). In the "pet dog” scenario, Chris would rationalise his preference for a cat differently. Perhaps assuming he just happens to be more of a "cat person" as he does not remember being bitten by a dog. As a result, he puts his preference for a pet cat down to the fact that he just happens to be more of a "cat person"- it becomes a matter of perceived preference rather than being driven by remembered experience. In both cases, Chris makes the same decision, but in the first example he is aware (conscious) of the underpinning reason for selecting a pet cat over a dog. In the second, he is unaware (unconscious) that his dislike of dogs has stemmed from a fear he developed as a child. I suggest that it is equally possible for conscious and unconscious motivators to play a similar role in the future choices made by Thanatophobic and Romantically motivated individuals regarding their adoption of radical life extension.

I have also based this discussion on the assumption that radical life extension is possible. I do not, therefore, spend time discussing particular scientific methods for radically prolonging the human lifespan nor practical issues such as access, distribution and population control, associated with this kind of technological advancement (Kass, "L’Chaim” 3-4). Below, a general definition of radical life extension:

- Radical life extension: entails the expansion of a person's lifespan far beyond what is currently humanly possible by eradicating aging and disease (Turner, B. 3). It is possible many people might eventually live to 1000 years, for instance (de Grey and Rae 325). Also note that a person with a biologically extended life span may still die from other causes, such as severe accidents. 
It is difficult to specify where moderate life extension ends and radical life extension begins. Currently, Jeanne Calment, who died at 122 years is the oldest (recorded) person to have lived (Robine; Jones 139). If one takes her age as the benchmark for current human longevity, then it is feasible to place moderate life extension in the realm of 120-200 years of life. While the borders of "moderate" and (the lower end of) "radical” life extension may be blurry there can be little debate that a life span of 400 or more years is sited in radical territory. This examination of life extension technology focuses only on technology that retains the biological human body (as we know it) by preventing disease and aging. Potential methods include stem cell research, genetic discoveries (Walker 581) and regenerating damaged cells (“Intro to SENS Research”). Limiting analysis to biological radical life extension works to funnel this discussion down; especially by omitting mind uploading and the potential associated issues such as digital clones or becoming part of the singularity (Kurzweil 325). It is also important to identify that in this context life remains finite and differs from immortality or eternal life (Turner, L. 121). While an immortal being will not die (via natural or accidental causes) a person with extended life will still, ultimately, meet death.

The examination of motivational factors affecting radical life extension and the TRM Spectrum framework has been divided into three parts:

Part 1: "Locating” - This section locates my analysis within psychological writing on motivation related to the fear of death and "love" of life, as well as the current radical life extension debates. I also present the philosophical arguments of significant radical life extension “players” in relation to their transhumanist, moderate enhancer and bioconservative positions. In so doing I aim to establish motivation as being an important, yet largely overlooked aspect of the radical life extension debate.

Part 2: "The Thanatophobic and Romantic Motivational Spectrum" - The second part of this thesis develops the core argument that motivation is central to considering whether radical life extension technology should be pursued and, if achieved, used. It is here that I establish the Thanatophobic and Romantic Motivational Spectrum (TRMS) as a framework for analysing why and how humankind might be motivated to pursue and respond to radical life extension technologies. I also define life extension technologies and apply them to the TRM Spectrum. 
Part 3: “Applications”: This section applies the TRM Spectrum, using the context of radical life extension, to areas of already significant ethical complexity - namely the death penalty versus life imprisonment, and euthanasia and suicide debates. Existing and future ethical issues are discussed in relation to radical life extension and the TRM Spectrum is tested as a framework for analysis of current and pending ethical issues.

These discussions are not intended to be philosophically or psychologically exhaustive and are limited to aspects I consider as relevant to radical life extension and the TRM Spectrum. 


\section{PART 1: LOCATING}

It is important to locate the Thanatophobic and Romantic Motivational Spectrum, and my core argument "that motivation is relevant and crucial to consider in the radical life extension debate”, within relevant literature. There appears to be a disconnect between the two disciplines of psychology and philosophy insofar as psychology speaks to death-related motivations for living or dying but fails to link these motivations to radical life extension, while philosophers discuss radical life extension without examining factors likely to motivate the decision to use the technology. The philosophical debate, instead, focuses on whether creating and using the technology is ultimately right or wrong, including associated practical issues such as access, population control and distribution. After identifying the gap in discourse related to radical life extension and motivation, and having explored the relevant literature, the only piece of aligned work I have subsequently found is Leigh Turner's 2004 paper “Life Extension Research: Health, Illness and Death.” In his brief analysis Turner “considers why individuals might have an interest in seeking increased longevity” (119). He similarly notes the absence of any substantive discussion on death-related motivations in the radical life extension literature (Turner, L. 119) - and this still seems to be the case fifteen years on.

This section provides a brief overview of the theories and research relating to motivation, life and death within the discipline of psychology, as well as the ethical debates about developing and using radical life extension within philosophy. I begin by investigating the psychological research that explores motivation, relating it to the "fear of death" (Thanatophobia) and "positive psychology”, which in its focus on human flourishing and "the good life" connects to Romantic motivation. The focus then shifts to radical life extension and related philosophical and ethical debates surrounding its development. Bio-conservative, moderate enhancer and transhumanist arguments are analysed as three key perspectives in the philosophical discourse. This leads into an analysis of arguments made by Thomas Pyszcynski and Leigh Turner especially. Both have begun the process of linking relevant aspects of the psychological and philosophical discussions together.

My analysis of death-related motivational factors in relation to radical life extension is intended to take the debate beyond a two-dimensional "right and wrong" mentality to one that is more nuanced and encourages deeper thinking on decision-making factors affecting the 
creation, use and management of radical life extension technologies. In developing the TRM Spectrum I have combined relevant ideas from both the psychological and philosophical disciplines to set the context for deeper examination.

\section{PSYCHOLOGY}

\section{1: The Fear of Death}

It is important to note the crucial influence of psychology when discussing the role of how we relate to, and are motivated by, our knowledge of death. Here, I briefly discuss two key psychological works that directly study and analyse death related fear as a motivation, including Stanley Hall’s 1915 article “Thanatophobia and Immortality” and The Denial of Death by (cultural anthropologist) Ernest Becker, alongside Terror Management Theory (TMT) (Soloman et al. vii-xi). My examination of these views is restricted to the key components of each argument. In addition, I situate the TRM Spectrum and possibility of radical life extension within the psychological literature and radical life extension.

Hall's analysis of death-related motivation discusses fearing death and loving life as foundational concepts related to the juxtaposed experience of living with an awareness of one's mortality and eventual demise. His statement that, the fear of death is only the obverse of the "love" of life and together they constitute the struggle to survive" (Hall 551), captures the essence of the TRM Spectrum which is designed to capture the nuances of radical life extension uptake by humankind. However, Hall’s work deviates from the TRM Spectrum in that he examines "love" of life and fear of death from a developmental perspective beginning with the idea that "love" of life is felt most strongly in childhood when the reality of one's mortality has not yet been properly comprehended. He then goes on to argue that fear of death is only developed in adulthood once the meaning of one's mortality has been fully realised. By privileging Thanatophobia over “love” of life, Hall’s examination of deathrelated motivation in my view is relatively one sided.

Hall then goes on to discuss the relationship between Thanatophobia and the human need for “immortality”. He discusses how people strive for an aspect of immortality which may include being remembered by others, leaving a legacy (such as a will), children and posterity and belief in an afterlife (Hall 581-585). Radical life extension and its relation to the immortality debate is not mentioned in Hall's analysis, probably because he was writing well before this technology was deemed possible. While Hall applies Thanatophobic 
interpretations to the various pursuits of immortality, he omits to mention more Romantically inclined motivations related to "love" of life. Whilst different forms of "immortality" might be used to moderate the fear of death, it can be argued that radical life extension presents a more "practical solution” to the mortality dilemma. In so doing, it makes understanding the role of motivation increasingly more relevant.

Becker also analyses fear of death in relation to one’s own mortality and, similarly to Hall, he excludes "love” of life, or Romantic motivations, from his arguments (xvii). This suggests that Becker implicitly assumes that fear of death is the main death-related motivation - or at least the only one worthy of consideration. He poses that humanity exists within a physical and symbolic duality. By this, he means that we exist in a known, mortal, sensory self within a world of physical objects as well as in an immortal, abstract world where the symbolic self is used as a means to overcome mortality (76-77) - an "immortality project” (Keen xiii). He goes on to explain the immortality project as a coping mechanism to avoid the anxiety produced through knowledge of one’s own mortality. Becker also suggests that an immortality project can consist of anything from religious beliefs to participating in social movements or creating art. The symbolic self is viewed as ultimately giving individuals meaning in their lives because they are part of something that is bigger than themselves which will outlast them. Like Hall, Becker does not extend his arguments to radical life extension technology and associated theoretical implications for extended life.

The Worm at the Core: On the Role of Death in Life expands on Becker's 1973 work resulting in Terror Management Theory (TMT) (Soloman et al. vii-xi). The concept of Thanatophobic motivation directly parallels TMT because this branch of psychology expands on "the role of the unconscious fear of death in just about everything we humans do" (Greenberg and Arndt 400). The results of a number of empirical research studies support this claim (Greenberg and Arndt 400). Terror Management Theory describes how recognition of one's eventual demise conflicts with the biological urge for self-preservation. It also discusses how life-preserving instincts and death awareness can work together to engender anxiety, or terror, which is consequently managed by the development of coping mechanisms related to social or symbolic systems (world views) that act to shield participating individuals from death-related anxiety. Adhering to a cultural world view is identified as important for personal mediation of anxiety and terror effects and for enhancing self-esteem (or personal value); particularly when an individual exists in a stable, meaningful world where they play a 
significant role (Pyszczynski et al. 2). In other words, a "cultural world-view allow[s] people to live... within a conception of reality” where they "view themselves as symbolic or spiritual beings who exist in a meaningful world, rather than as mere transient animals fated only to obliteration upon death” (Greenberg and Arndt 402). Once again, the Romantic motivation (or "love" of life) is overlooked as an important motivating factor in its own right, being reduced down to a product of fear through the "cultural world view" TMT posits. Focus is placed on death-related fear - the "worm at the core” (Soloman et al.) - as the only relevant life and death-related motivation for any conscious, living being.

\section{2: Positive Psychology and Existential Positive Psychology}

Positive psychology is another branch of psychology and an area that aligns with the hitherto overlooked Romantic aspects of the TRM Spectrum. Where Becker and TMT focus primarily on fear-based motivation related to the knowledge of certain death, positive psychology provides an important counterbalance by aligning with the more Romantic concept of what “makes a life worth living” (Seligman and Csikszentmihalyi 5). Positive psychology as a field of study was initially conceived after World War II in response to the emphasis being placed on pathology in psychology. It aimed to catalyse a "change in focus in psychology from preoccupation only with repairing the worst things in life to building positive qualities” (Seligman and Csikszentmihalyi 5). This shift in perspective is subtle but important, because it relates to positive life experience rather than more negative aspects such as "endurance in adversity”. The Romantic motivation echoes this shift in perspective by focusing on life, and the various reasons why one chooses to live, as a core motivation equal to the fear of death.

The "good life" is discussed broadly within positive psychology and touches upon aspects such as human flourishing, happiness, well-being, and personal characteristics including wisdom and creativity (Hefferon and Boniwell 2). Martin Seligman, for instance, explores three possible routes to reach "authentic happiness", including: the "pleasant life" (hedonism theory); the "engaged life” (desire theory); and the "meaningful life” (objective list theory) (Sirgy and $\mathrm{Wu}$ 183). He links the pleasant life to hedonism because it focuses on maximising pleasure, including sensory pleasure, and minimizing pain. He suggests the engaged life is about gratification or getting what one wants (which is subjective to the individual) and includes truth or illumination via engagement, thereby transcending hedonism. The meaningful life goes a step further in purporting that happiness is derived from worthwhile pursuits such as education, knowledge, freedom, relationships and goals (Sirgy and Wu 184). 
Models such as that of Seligman assist to describe aspects of the Romantic motivation. Individuals who are living their version of the good life are likely to be more Romantically inclined and, therefore, more likely to opt to extend life for as long as they enjoy it and feel fulfilled; whether it be for reasons associated with satisfying bodily pleasures, mastering a skill, extending a meaningful relationship and/or accomplishing a long-standing goal. From this perspective Romantic motivation is not merely a derivative of Thanatophobia, as assumed by Becker and TMT, but rather stands as an important motivator for extended life in its own right.

Paul Wong and Adrian Tomer also tie positive psychology to fear of death, called 'existential positive psychology'. They sum up this view in the statement, "our relationship to death cannot be reduced to terror, a complete psychology of death needs to move beyond terror and denial and start investigating positive attitudes towards death” (Wong and Tomer 100). Wong also writes in favour of "existential positive psychology", a subsidiary of positive psychology explicitly concerned with analysing the "joy of living" (1), as a counterbalance to predominant existential psychology and TMT arguments focused on fear of death. From this point the similarities between the TRM Spectrum and existential positive psychology diverge because Wong and Tomer concentrate only on how one can use acceptance of death to live an “authentic” and meaningful life (104). The theories from positive and existential psychology appear quite prescriptive in nature because they propose methods to achieve "the good life. While these views provide a useful frame of reference to describe aspects of the Romantic motivation, the TRM Spectrum is ultimately a descriptive framework. It describes what might happen if you took a course of action but does not suggest you do it - in this case, why and how individuals might utilise radical life extension if it is available in the future.

The TRM Spectrum does not attempt to judge whether its key motivations are ultimately conducive to a person's “quality” of life. So, whilst living a happier and more fulfilling life might foster a stronger Romantic motivation, it is not necessarily essential to it. A person actively addicted to heroin, for instance, may have stronger Romantic motivations on the TRM Spectrum because they are more focused on experiencing the high (or pleasure) the drug delivers through gratifying their addiction. The potential risk of death via an overdose is a secondary consideration in this type of scenario. It is possible also that a person with this sort of addiction will opt to radically extend their life (where the option is available to them) because they are predominantly motivated by the idea of spending as much time as possible 
getting high. I acknowledge that the nature of addiction is far more complicated than I describe here. However, it is a useful example to show that, while the life of a practising heroin addict is unlikely to be judged as a "good" or "flourishing" life by those in the psychology discipline, it is still possible for them to be Romantically motivated.

\section{3: Concluding thoughts}

The separate areas of psychological research presented thus far show Thanatophobia and Romanticism as being two connected but distinct motivators. The analyses of Hall, Becker and TMT connect to a Thanatophobic orientation, while positive psychology and existential positive psychology portray elements of the Romantic motivation. I have aimed to locate the TRM Spectrum within an existing foundation of psychological theory and research and in so doing, have identified that in certain instances the TRM Spectrum diverges from this thinking and enters new territory. This is perhaps because there is very little overlap between TMT and positive psychology, even though existential positive psychology also applies the research to death awareness, As a result TMT and existential positive psychology motivation provide relatively one-sided discussion of motivation related to death - and life. The fear of death and "love of life" are not properly linked together as a framework for analysis as in the TRM Spectrum posed in this thesis.

Additionally, death-related motivations described in TMT and (existential) positive psychology are not applied to radical life extension, which from a philosophical perspective is an area this thesis seeks to fill. The line of analysis taken by Becker and TMT in their immortality discussion offers an interesting parallel to the radical life extension debate. However, it differs because radical life extension (though it does not entail immortality) gives humanity greater control over death - especially the "when” part (with the exception of deadly accidents that still have the potential to terminate life). I pose that the introduction of radical life extension will also act to change the way we relate to life and death, and that our motivation to extend/end life will become an important future consideration. A framework such as the TRM Spectrum postulated in this thesis is likely to help those deciding whether or not to utilise radical life extension to consider - and in the process, better understand - why they are inclined to potentially use the technology. 


\section{THE PHILOSOPHICAL DEBATE}

Radically extended life is the focus of significant attention from philosophers who debate this issue from a number of perspectives, namely bio-conservative, moderate enhancer and transhumanist viewpoints. These are discussed as a precursor to the second part of this thesis where the TRM Spectrum will be expanded on. By locating the motivational Spectrum within the current philosophical debate, I will show how motivation has been mostly disregarded as a key point of consideration. In the process, I intend to further reinforce why motivation is important to consider in relation to the current development, and potential use, of radical life extension technology.

\section{4: The Bio-conservatives}

Bio-conservative individuals, such as Francis Fukuyama and Leon Kass, represent the sceptical end of the radical life extension debate, opposing the transhumanist position (and optimism) in relation to the use of bio-technology (Fukuyama 6-9; Kass, Life, Liberty 3, 7-8). They approach bio-enhancement with extreme caution and see it as a technology with important practical and political implications (Fukuyama 6-9; Kass, Life Liberty 3-8). And as the potential for being an enhanced post-human looms ever closer, they also consider the value of being human, defined by Fukuyama as comprising our "natural desires, purposes, traits, and behaviours [as a] human whole” (12). Peter Singer’s 1991 paper "Research into Aging: Should it be Guided by the Interests of Present Individuals, Future Individuals, or the Species?” also expressed a bio-conservative argument using utilitarianism ${ }^{1}$; a consequentialist ethical framework that judges the morality of an action based on whether it maximises or decreases the net utility, or "good”, such as pleasure or well-being (Mill 9-10). He contends that life extension technology should not be developed because living to 150 years (a moderate form of life extension) would result in lower aggregate utility (Walker 581). While the bio-conservative resistance to radical life extension technology represents an important position within the philosophical debate, the role of psychology and motivation is not properly examined as an important component of the discourse.

Fukuyama's concerns about bio-enhancement include the development and potential use of radical life extension technology. He defends the notion of human nature as a legitimate

\footnotetext{
${ }^{1}$ Singer is placed as a bio-conservative here based on the arguments made in this 1991 publication.
} 
concept endangered by a potential post-human age, especially because biotechnology has the potential to challenge the idea that all human beings are born equal in nature. Radical enhancement could mean we are no longer human as we are now, but something “other”. Fukuyama argues that this is a significant issue requiring serious consideration (5). To enter a post-human phase of history will entail an alteration of human nature, “a meaningful concept [that] has provided a stable continuity to our own experience as a species” (Fukuyama 7). He argues also that human nature provides an important foundation for the notion of human rights and that biotechnology such as life extension could have considerable political consequences (Fukuyama 15). The concepts of human rights, human nature and human dignity are explored in detail by Fukuyama, but again there is only passing acknowledgement of potential motivating factors that are likely to drive a desire for human enhancement including life extension.

Peter Singer's 1991 paper aligns with the bio-conservative view but uses a utilitarian analysis to judge whether life extension technology should be developed and potentially used. Using the lens of opportunity cost, Singer suggests that life extension technology would lower the aggregate utility and as a result he concludes that "we should recommend against any further development of the anti-aging drug” from a utilitarian standpoint (144). Singer's discussion focuses primarily on moderate rather than radical forms of life extension - a scenario where the average human lifespan is doubled from 75 to 150 years. He stipulates also that while a lifespan of 150 years would be manageable, it is unlikely to be as fulfilling as the first 70-80 years of a person's life (Singer 139). His research draws on a thought experiment showing how two groups of 6 million people living for 75 years produce a greater net utility because of their better health and fresher perspectives than one group of 6 million people living for 150 years (Walker 591-593 ). His views, because of their "happiness measures” can be linked to the Romantic end of the TRM Spectrum. However, consequentialist ethical frameworks, such as utilitarianism, focus on the outcome of an action rather than the motivating factors that lead to the individual agent's decision to perform it. Singer's argument is no different, and motivation is once again omitted from his discussion of life extension.

Kass does allude to the role of desire in relation to life extension, and in this way seems to align more closely with my discussion of motivation than Fukuyama and Singer. He predominantly develops the argument that humanity is "adrift without a compass" (Life, Liberty 46) and that the continuing development of biological technology is leading humanity 
into open, uncharted waters, and questions how we can judge life extension as "good" or "bad" if we have not yet found our bearings. Kass notes also that we live in a time where technology is beginning to push the very notions of life and death and that the relative value of death and life must also be considered. The role of desire in the decision to use radical life extension is noted, where the desire to live longer is linked to "the desires of the majority for whom attachment to life (or fear of death) knows no limits” (Kass, Life, Liberty 263). Though the term “desire” is used instead of “motivation”, Kass's statement does align to the TRM Spectrum and seems to imply some consideration of concepts like the fear of death and "love” of life in relation to life extension. However, such contemplation appears to be shortlived, as he does not expand on these ideas - seemingly in the assumption that the problem is best solved with the "simple answer" that "we want to live and live, not to wither and die" (Kass, Life, Liberty 263). In this way, motivation for radical life extension use is touched on at a surface level only, without deeper analysis.

The arguments of bio-conservatives like Kass, Fukuyama and Singer act as an important counterbalance in the life enhancement debate to the transhumanist position that champions the development and use of radical life extension. To question the benefits of radical life extension does not necessitate a complete rejection of it, but illuminates potential negative consequences of the technology. Instead of looking to the rosy glow of a potential posthuman future, they are grounded in the present exploring the implications of developing and using bio-technology which allows radical life extension. In so doing they question the wisdom of allowing ourselves to race into a murky, post-human future without properly considering what it means for 'being human' as we currently understand it. Though Kass does briefly discuss why one might opt for radical life extension, the role of motivation is not explicitly examined in bio-conservative arguments.

\section{5: Moderate Enhancers}

Moderate enhancers such as Nick Agar occupy a middle ground by supporting moderate life extension rather than radical life extension. A “moderately" extended life refers to an enhanced life span that does not stretch far beyond the current limits of human longevity (Agar, Truly Human Enhancement 2). If the average human life span is, say, 80 years for those with good living conditions and no sudden accidents, adding another 50 years of life would seem reasonable. Living to 130 years, for instance, is not much longer than supercentenarian Jeanne Calment and can, therefore, be described as moderate (Agar, Humanity's 
End 2. As previously stated, the boundary between moderate and radical life extension can be unclear, but as numbers climb upwards to 300 or more years any initial fuzziness disappears into a radical, unknown territory.

This position welcomes some technological enhancement but does not accept the necessity of radical, post-human, life extension technology. Agar reasons that believing endorsement of moderate enhancement automatically entails radical enhancement is akin to the idea that to have one glass of wine means you must drink the whole bottle ("Thoughts about our species" 24). He makes an important and valid point - life extension technology does not have to be viewed or used in the extreme; there are alternatives. While the TRM Spectrum can be applied to moderate and radical life extension in similar ways, it is likely that an individual who opts for moderate life extension use will potentially express these motivations in a less extreme way than their transhumanist counterparts. I pose, because of much stronger Romantic motivations, this kind of person might decide to add another 75 years to their lifespan to complete an important project they have undertaken and will happily welcome death once it is completed and their time is up. A more Thanatophobically motivated individual may comparatively find it far more difficult to bypass the opportunity to live longer and thereby avoid death

As already argued, the TRM Spectrum provides an additional layer through which to analyse the complexities of life extension, and, in a similar way to Agar, to, "move beyond the binary 'yes, I love it; no, it’s evil' dialectic that has tended to dominate philosophical discussions to now” (“Thoughts about our species” 23). Agar highlights a key issue within the current life extension debate, characterised by individuals who either strongly advocate for, or vilify, the technology without seriously considering the merits of the opposing view, particularly in relation to the possibilities a middle position presents. While I agree with Agar on this point, the TRM Spectrum offers a more neutral approach in relation to the 'rights and wrongs' of radical life extension and instead offers a way to explore in a more nuanced and deeper way the potential responses of humanity to, and implications of, radical life extension.

\section{6: The Transhumanists}

The term transhumanist is used to describe individuals who support technology that will radically enhance humankind - physiologically, psychologically and intellectually - beyond the present human standard: making them “post-human”. Life extension presents as one such 
technology by maximising the capacity of human health and overall lifespan. Aubrey de Grey, Nick Bostrom and Mark Walker are proponents of radically enhancing the human lifespan. From their transhumanist standpoint aging is viewed as a disease - the ultimate cause of death - and a biological defect to be eradicated (de Grey and Rae 21). De Grey (and co-author Michael Rae), in fact, go as far as stating that devoting resources to diseases such as cancer and Alzheimer's disease does not make sense without focusing on aging itself, which causes 100,000 unnecessary deaths daily (8).

De Grey is actively researching rejuvenation technology, or Strategies for Engineered Negligible Senescence (SENS), at the SENS Research Foundation he co-founded ("Executive Team”). He also laments the "pro-aging trance”, as a psychological stance in which one will irrationally defend the concept of aging as a necessary and inevitable occurrence. According to de Grey and Rae, a person blinded by the pro-aging trance may be upset by an agingrelated disease, but not aging itself (9-17). De Grey and Rae believe that we are in a period he calls "the War on Aging”, which he describes as "the period beginning with the destruction of the pro-aging trance and ending with the widespread availability of therapies that can add a few decades to the lifespan of people who are already middle aged” (212). Part of this war rests in convincing the general public that it is possible to eradicate aging. Bostrom's paper “The Fable of the Dragon-Tyrant” endorses this viewpoint by presenting aging and death as a terrifying dragon that unleashes tyranny upon the people. The dragon is thought to be indestructible, but technology eventually evolves to a stage where it can destroy the dragon. When this occurs, the people cry out in joy because they are free of the oppression suffered for centuries (Bostrom). The allusion here is that once aging is eradicated, humanity will receive the ultimate gift - freedom from the death-bearing “tyrant”.

Bostrom, too, refers to the “'Deathist' stories and ideologies” that encourage a "passive acceptance” of aging and death (276). Deathism” is the term used to describe the notion that death is an inevitable occurrence we must all learn to accept, and ties into the pro-aging trance (Bostrom 276). Like de Grey, Bostrom argues that such views, whilst justified in the past when radical life extension was not technologically viable, are now limiting the progress of a hugely beneficial technological advancement due to disbelief and/or suspicion regarding radical life extension. Deathism and the "pro-aging trance” are used to explain why opposition towards radical life extension exists. It is thereby unsurprising that transhumanists, in their enthusiastic advocacy of increased longevity, view concepts like deathism and the 
“pro-aging trance should” as unnecessary, dangerous barriers to development (and potential use of) the technology (Agar, Humanity’s End 109; Bostrom 276; de Grey and Ray 9-17). This view thereby differs to the TRM Spectrum which instead explores why one would opt for radical life extension without making a value judgement. Ultimately though, de Grey and Bostrom still fail to move beyond the binary perspective of the "death bad, extended life good" mentality. As with other writers, while the transhumanists strongly favour radical life extension, they give scant consideration to the role of motivation. Indeed, it appears to be assumed that people should want to eradicate disease and aging to live a healthier - and radically longer - life. The nuance of motivation, especially its potential impact on how the technology may be used is not properly examined.

Walker's support for radical life extension (or "superlongevity" as he calls it) takes a slightly different line to the views of de Grey and Bostrom, in that he directly opposes Peter Singer's utilitarian bio-conservative position (described above) with his own utilitarian argument. Walker speculates that if life extension technology becomes easily accessible, people will have a choice to self-elect out of or into using the technology, leading into the conjecture that happier people will be more likely to use it than those who are less happy (591). He explains three ways people might 'self-select' out of radical life extension; namely, suicide, refusing the technology or incorrectly following medical prescriptions designed specifically for life extension (Walker 591-593). In Walker’s “self-selection” scenario, life extension technology is presented as increasing aggregate utility because in his view the majority of people who will choose to increase their lifespan are likely to be happier with life (591). From this utilitarian standpoint, it follows that developing and using radical life extension is more ethically permissible than not doing so because it will increase the aggregate utility, in this case, pleasure.

Walker, like de Grey and Bostrom, does not explicitly explore motivation and the associated implications in his defence of super-longevity. I propose though that there are echoes of a Romantic motivation in his argument that happier people will "self-select” to live longer while unhappy people are less likely to do so (Walker 591). However, there are other aspects of a Romantic motivation that do not directly link to individual happiness, such as greed or a sense of self-importance, which are not suggested as reasons why one might continue to opt for radical life extension. Furthermore, the fear of death is not examined as another key factor influencing ‘self-selection’ like happiness. In this scenario a population with a high 
proportion of people with stronger Thanatophobic motivations, who are also unhappy and self-select to use the technology, would potentially lower the aggregate utility. It is also possible a group of 'happy' people with predominant Thanatophobic motivations would result in a higher aggregate utility, as Walker speculates. Whatever the case, this example serves to illustrate how it is important to move beyond binary considerations and to consider more nuanced interpretations of the moral permissibility and possible results of developing and using radical life extension.

\section{PYSZCZYNSKI AND TURNER}

\section{7: Thomas Pyszczynski - TMT and negative reactions to radical life extension}

It is important to explore in more depth the work of Thomas Pyszczynski, a founder of TMT, as he links the motivational role of death-related fear to radical life extension. Pyszczynski's work utilises death-related motivation (from TMT) to explain the "paradox that many object to the idea of a long term extension of the human lifespan” (Pyszczynski 01:26-01:32min). Rejecting radical life extension technology is presented as being paradoxical from a TMT perspective due to the reliance the theory places on fear of death as the ultimate motivating factor and explanation for (a lot of) human behaviour. From this standpoint, it follows that more people should be jumping on board the pro-radical life extension train and supporting its development given the potential for radical life extension to practically postpone death for hundreds of years. Pyszczynski explains deathist opposition to the development of life extension technologies as being entrenched in the challenge that radical life extension presents to the cultural worldviews people develop to give meaning to their lives and manage the terror of death. This theory was also presented at the 2013 conference hosted by the SENS Foundation (Pyszczynski 00:00-26:20min), the not-for-profit organisation co-founded by the transhumanist Aubrey de Grey and others, to research the eradication of age-related disease (“Intro to SENS Research”). Transhumanists such as de Grey view deathism as an unnecessary impediment to progressing the development of life extension technology.

Pyszczynski does not discuss the reasons why one might decide to live (radically) longer, perhaps because he assumes that the driver would be Thanatophobic, a perspective that aligns with TMT and the idea that decisions to create and potentially use radical life extension can be reduced to the simple explanation of "nobody wants to die” (Pyszcynski 00:15-00:30). Although Pyszcynski considers the motivating role of fear of death in relation to radical life extension uptake, his discussion fails to capture the nuances of human decision-making - just 
as other current philosophical debates fail to do. While fear of death may appear to be especially relevant to the current, shorter existence of human life, radical life extension might shift the focus so that the "love" of life is also seriously considered - especially where fatal diseases and accidents are avoided. Furthermore, having an immortality project to manage fear of death does not fully capture the meaning of life and how one consciously experiences the world. For instance, forming meaningful relationships with others can be explained as an aspect of one's immortality project, but does not necessarily capture the fulfilment that can result from positive interpersonal relationships. Similarly, limiting the experience of a couple who decide to have children as a result of some deeply rooted need to 'extend' their life via more abstract means (in this case, posterity) does not explain the subsequent joy and meaning the couple experiences from loving their children.

\subsection{Leigh Turner}

I have previously noted how my research into motivation and radical life extension has identified Leigh Turner's 2004 health-related analysis as more closely aligning with the conceptual framework underpinning the TRM Spectrum than any of the other works examined during its development. Turner identified a similar gap stating that "with many commentators focused on ethical, legal, social, economic and institutional problems associated with [increased longevity], it is easy to overlook why [it] might have considerable appeal” (Turner, L. 119). An argument supporting or opposing life extension is not provided. Turner instead seeks to explore why individuals might want to develop and potentially use the technology if it is created (126). His examination also evaluates the role of death-related fear, alongside a fear of dying and good health. In analysing the fear of death, Turner's work explicitly cites TMT (119), thereby, linking into the Thanatophobic motivation used in the TRM Spectrum. Though he does not directly discuss a “love” of life, aspects of Turner's analysis of good health can be related to it. For instance, the importance of good health "as a basis for many of life’s pursuits and pleasure” is outlined "even if [one does] not fear dying and death” (123), which captures aspects of the Romantic motivation. For these reasons I believe there is some alignment between Turner's discussion and the basic premises of the TRM Spectrum.

However, Turner's analysis is fleeting and fails to develop these ideas beyond their basic premises. Much of his discussion also diverges from the topic of motivation. For instance, Turner’s segment about “good health” expands on the concept of healthier living only (122- 
126). Much of this section centres on incremental developments in healthy living as it is currently, with anti-smoking campaigns and social welfare programs cited as moderate forms of life extension (125). Though the "healthy living" segment has some relevance to the Romantic motivation, motivation regarding life extension is generally put to the side in favour of potential ways it might be achieved. Turner's intent seems to have been to present an introductory overview of factors that might contribute to interest in extending the human lifespan. While he succeeds in this, he does not ultimately go into enough depth to form a conclusive argument about why the role of motivation should be included as a crucial part of the radical life extension discourse.

This is where I believe our analyses deviate. In this thesis, a conceptual framework (the TRM Spectrum) has been created to guide a deeper investigation of motivation and radical life extension by building on ideas from the philosophy and psychology disciplines relating to radical life extension, the fear of death and "good life". The role of motivation is examined in far greater depth than in Turner's analysis. Applying the motivational Spectrum as a framework to consider contemporary ethical issues related to life, death and possibly radical life extension, also works to further develop the TRM Spectrum as the various parts tie together, and in so doing, strengthen the case for consideration of motivation as a key aspect of the radical life extension debate.

\section{9: Concluding thoughts}

Motivation has surprisingly emerged as being largely absent in the life extension literature from both psychological and philosophical perspectives apart from the brief paper published by Leigh Turner over a decade ago. Yet, as Turner and I have argued, it is an important component to include in the debate if we are to understand how human beings may use and respond to this technology. Fear of death and appreciation, or "love" of life are complex motivators, and are not necessarily mutually exclusive. By developing the TRM spectrum I attempt to link them together to provide a more comprehensive examination of motivation related to life, death and radical life extension. The reason why we pursue, or use any technology can have a huge impact on how it is treated and what it means to be human. If humanity wishes to fast forward into a future where radically extended life is possible, we need to be clear about the reasons we are doing this, both at individual and societal levels. 


\section{PART 2: THE MOTIVATIONAL SPECTRUM}

\section{THANATOPHOBIC AND ROMANTIC MOTIVATION AS EXPERIENCED BY THE INDIVIDUAL}

\section{1: Are you afraid of the dark? Our motives for extended life}

Why then are people currently trying to develop technology with the potential to radically extend the human lifespan? And if they succeed, why is it likely that people will be tempted to use it? I argue that this is dependent on how humans relate to life and death at a fundamental level and that it might express itself in different ways. Though various theories have been postulated about the existence (or lack thereof) of an afterlife, this area remains a mystery; the one known being that at some inevitable point every person who is born will exit their body and die. No matter how objective one's view on what happens at death it remains a mystery of life. Death can also be a source of great anxiety that is likely to influence the reasons why various people may pursue life extension technology. I believe that Thanatophobic and Romantic motivations as conceptualised in this thesis are crucial to analysing why people may view life extension as desirable.

To illustrate how many of us relate to potential death I use the analogy of it being a journey/ a solitary walk down a dark passage. Each step forward is met with a light (or "life”) switch you flick to turn on the corresponding light that weakly illuminates the immediate area. To turn back is to gaze upon your past; the closer lights are brighter than those further in the distance. Ahead of you, in the future, there is only darkness. Its secrets are only revealed with every step forward, each lamp flicked on. Light is reassuring because it allows for sight and some clarity, whereas the darkness seems ominous - it represents mystery and blindness, a huge lack of control. You are compelled onwards despite knowing for certain that one day the light won't turn on. When this happens it is beyond your control; all you know is that you will eventually be plunged into darkness. These feelings create a perplexing synthesis of love and fear. Love for the comfort of light, and fear of the darkness, or unknown. The duality of these emotions can create an intensified, more potent reaction to the forthcoming darkness and it can become difficult to distinguish the splendour of the light from the fear of the unknown. 
This analogy serves to highlight how I believe many of us relate to the prospect of death - an unknown quantity - and consequently, how many of us might relate to life extension if it were to become a reality. Existence, or lack thereof, after death is not the central concern here, but rather, the relationship we have to it as existent, conscious beings who are aware of the reality of death but cannot know for certain what it actually entails. When other people pass away, "we are always just there alongside” (Heidegger 282; div.2, ch.1, sec. 47). Death cannot be fully experienced and known until the moment it strikes (Sutton 1).

The light switches and consequent light characterise life. The darkness in front signifies the unknown of death. We continue stepping forward, or living our life, aware the clock ticks and uncertain as to when death will hit. The synthesis of knowledge and uncertainty is represented by the faulty light switch; we know it exists, as death must surely come, but we do not know exactly when. In this analogy, the walk is solitary and reflects Heidegger's views on the subject of death and how it must always be faced alone, with this "aloneness" potentially compounding the anxiety surrounding death. In the words of Heidegger "every Dasein must itself actually take dying upon itself. Insofar as it 'is,' death is always essentially my own” (Heidegger 284; div. 2, ch.1, sec. 47). Ultimately, though, the analogy echoes the sentiments expressed by the Simone de Beauvoir quotation used to open this thesis (268). The person walking down the hallway can acknowledge the darkness, or death, Romantically, by allowing it to brighten the light, or alternatively they can become fixated on the imminence of death and, in doing so, become enveloped by an obsessive, Thanatophobic fear of it. Like de Beauvoir, they may well experience both simultaneously.

Humans are complex creatures and cannot be easily labelled. For this reason, the TRM Spectrum has been developed to capture the various and potentially changing levels of Romantic and Thanatophobic motivation an individual may experience during their lifetime. It is probable that an individual's position on the Spectrum will fluctuate throughout their existence as they respond to different life circumstances and changing psychological states. For instance, an individual may experience the death of a loved one or narrowly escape death themselves with the effect that for a period they become more transfixed on the "darkness of their hallway” than previously. Conversely, a person who skydives for the first time may feel terrified but exhilarated and filled with a more intense "love" of life for a short time. One must also account for the fact that self-deception may come into play where individuals consider themselves to be Romantically motivated when in fact fear of death is the key 
influencer on many of the actions they take in their lives. Nevertheless, the focus here is placed on characterising the more extreme ends of Thanatophobic and Romantic motivation and to demonstrate how they are connected yet distinct from each other. It is also possible that some people may not experience these motivations very acutely and instead hover somewhere in the middle range of the Spectrum (a moderate position). The Thanatophobic and Romantic distinction as described is intended for use as a framework to consider issues concerning our relationship to life and death, why life extension technology is being developed, and why we are likely to use it (or not) if it is successfully created.

\section{2: "I have more living to do" versus "I don't want to die"}

These statements simplistically capture how Romantic and Thanatophobic motivations differ in relation to influencing a desire for radical life extension technology. Each statement expresses a motivation for extended life, but the focus of each differs depending on its emphasis. "I have more living to do" suggests a Romantic view where the motivation and focus is on living. A person who is more Romantically motivated wants longer life because they enjoy being alive. Conversely, the second statement “I don’t want to die” encapsulates a Thanatophobic motivation because the focal point is death. Although a Thanatophobically motivated individual may enjoy being alive, their attention if clearly sitting at this end of the Spectrum, will ultimately be directed at the prospect of dying rather than living.

The Romantically motivated person utilising life extension technology is likely to do so to prolong the joys of living. De Grey’s proposition that life extension technology leads to a healthy, longer-lived utopia where people can pursue their dreams without the time constraints we face in our present, shorter-lived condition aligns with this view (Agar, Humanity's End 108). Time and health are unlikely to be the constraints they currently are, and life extension will allow humans to make the most of the opportunity's life offers. They will be able to pursue passions and "live many lives" without current time limitations. If the key motivator is to enjoy a fulfilling life, it makes sense that a Romantically driven individual will make the most of any activities that pique their interest. For instance, they may pursue hobbies such as mountaineering at age 100 before taking up carpentry at 250, and have multiple, varied careers which may include becoming a rock star, skydiving instructor and barista between the ages of 200 and 500 (Agar, Humanity's End 108). Life extension technology would be utilised as an opportunity for exploration, enjoyment and meaning. As a tool to make the most of living. 
In my mind, a Romantically motivated person will also be better equipped to stop using life extension technology (and therefore accept death) if they stop enjoying life; or, on a societal level, the technology is proven to impede rather than improve life quality (although this may also depend on an individual's social conscience). The recent news of Australian scientist David Goodall's choice to end his life at 104 years of age presents an interesting case study regarding radically extended life and euthanasia (Retcher et al). Although elderly, Goodall had retained good physical and cognitive capacities, he wished to die because he was no longer happy. When asked about his imminent death, he stated how "it's not sad particularly. What is sad is if one is prevented” (Bever). In this way, Goodall can perhaps be viewed as a potential example of those with dominant Romantic motivations in the future. Having lived a long and fulfilling life Goodall was able to welcome death as a friend when he no longer appreciated living.

It is important to note, however, that an individual who falls at the extreme end of the Romantic motivation Spectrum may not have the same capacity to choose death over life. This presents an interesting aspect of the Romantic motivation, which at first glance might appear to be far healthier than an overt Thanatophobic motivation. At its extreme the Romantic motivation can encapsulate characteristics that are often viewed as negative such as lust for power, prestige, ego or overt hedonism. I pose that while on the surface Romanticism can appear as an innocuous driver for life extension it is possible that a Romantically motivated individual (who has lived a radically extended lifespan) and who displays more egotistical or hedonistic characteristics may over time view death as a foreign concept. To be ultimately driven by one's own self-importance is a Romantic motivation and could result in this individual justifying the necessity of their radical life extension use because their existence is critical to the world in some way. Similarly, a person with stronger hedonistic Romantic motivations might become so accustomed to living life for the enjoyment it offers that they lose sight of mortality as an option.

Leon Kass makes an interesting connection between "brave new technology" such as life extension and Aldous Huxley’s famous 1932 dystopian novel A Brave New World, where it “goes with, rather than against, the human grain” (Life, Liberty 5). In Huxley’s society, humanity has eliminated issues such as poverty, disease, war and negative emotions such as grief and anxiety but the trade-off for these benefits is dire. There is a lack of depth, a lack of 
humanity where "bodily health and immediate gratification" are now the highest aspirations (Kass Life, Liberty 5). Enjoying life, as the Romantic desires, is all very well but this kind of motivation could also be dire if taken to the extreme. In Huxley’s world, the drug Soma symbolically encapsulates an excessive Romantic motivation. Soma is used to eradicate all pain and to give people immediate pleasure, in a world where individualistic pleasure (however expressed) trumps anything else. It is possible that a society with extreme Romantic motivations would eventually take on the hue of Huxley's Brave New World - where people live only to fulfil the next desire life presents.

In this way, the Romantic motivation aligns with the extreme Thanatophobic motivation, as each have the potential to render an individual incapable of choosing death - they are both on a continual quest for longer life. It is of course possible for a person at the extreme end of either motivation to become less so over time, but some individuals may equally remain extremely Thanatophobic or Romantic. A person strongly motivated by Thanatophobia is terrified by the uncertainty, or lack of control death represents, and the fact we must ultimately meet it alone (Heidegger div. 2, ch.1, sec. 47, 284). While life extension technology such as SENS will protect against aging and disease, it does not insure against accidental death, thereby making it likely that strongly Thanatophobic individuals will be mindful of this point and go to great lengths to postpone death, including avoidance of dangerous activities such as paragliding that may otherwise have been of great interest to them (Agar, Humanity’s End 123).

This perspective aligns with an interesting critique of life extension by the philosopher Nick Agar, where he argues a case based on the concept of fear and risk aversion. Agar predicts that people with extended life spans will distinguish between "sudden and gradual causes of death” and live accordingly (Humanity's End 123). A possible result of this shifted emphasis may be that people will live different kinds of lives and that certain hobbies considered high risk, such as travelling to dangerous countries and skydiving, may “die out”. This argument suggests that an implication of radically extended life and a possible reaction related to Thanatophobia, is that a person who has gone to the necessary lengths to increase their lifespan will bypass anything that unnecessarily puts their life at risk and in so doing live a less meaningful and more constrained life that is consumed with avoiding danger and potential death. In this, extreme Thanatophobic motivations differ from those of dominant Romantic motivations, where fulfilling ways of life are more likely to be highly valued even if they put an individual at risk of unexpected death. 
Within these scenarios there is also potential for extremely Thanataphobically and Romantically motivated individuals to abuse the technology due to selfish and irrational behaviours related to death avoidance being the ultimate goal. In this context understanding what motivates people in relation to life extension is crucial to ensure that it is utilised in a beneficial, equitable and managed way. The TRM Spectrum provides a useful framework for reflection on these matters at both personal and societal levels - to understand and prepare for a world where life extension technology is a reality.

\section{EMPATHETIC AND SOCIETAL MOTIVATION}

\section{3: Motivation beyond the individual}

So far, I have presented and explained the Thanatophobic and Romantic motivational distinction from an individual perspective, the one that is "I" facing, and wishing to postpone, the prospect of their own death. I call this “Individual motivation”. I now briefly touch upon two other important motivational factors relating to the individual within a broader context, which I refer to as "Empathetic" and 'Societal" Thanatophobic and Romantic motivations. Empathetic motivation in this context is where an individual's Thanatophobic and Romantic motivations relate to the life extension of other people while Societal motivation draws on broader societal influences, such as culture, the media, and the laws of a given society. These are complex areas to navigate as it is difficult to capture the range of views and actions different people within a larger population, especially with respect to how Societal and Empathetic features are likely to influence radical life extension approaches. It is not my intention to discuss Empathetic and Societal motivations at great depth, as they require more attention than this thesis is able to provide. It is nevertheless important to touch upon their crucial influence.

To show this more clearly, I have adapted psychologist Urie Bronfenbrenner’s “bioecological systems model” (Vélez-Agosto 902). It was initially designed by Bronfenbrenner to show the relationship "throughout the life span, between a growing human organism and the changing immediate environments in which it lives... as well as the larger social contexts, both formal and informal, in which the settings are embedded” (“Toward an Experimental Psychology” 514). This modified version in Figure 1 shows how the three layers of motivation (Individual, Empathetic and 
Societal) might interact together and influence each other taking into account similar contextual elements.

Figure 1:

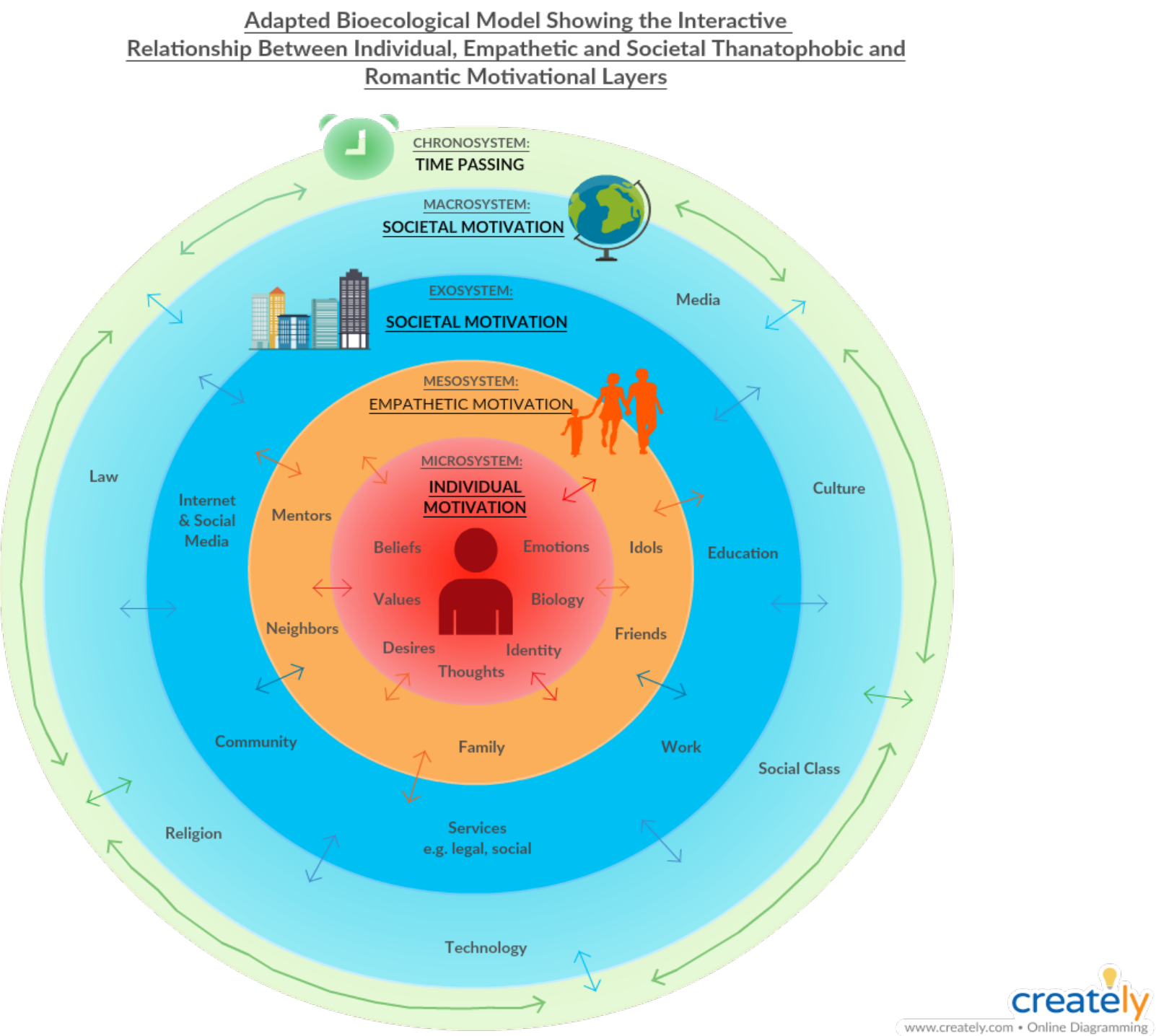

\section{4: Microsystem to the Chronosystem}

The systemic layers are simultaneously distinct and inter-related. The central layer, or Microsystem, is the most intimate of the five and is where the individual is sited, and then influenced, by the outer layers, each of which build on each other until the more remote Macrosystem level is reached (Bronfenbrenner "Ecological Models” 38-40). 
The Chronosystem wraps around the other layers to represent the influence of time. It can take the form of direct, personal events happening in the Microsystem and Mesosystem, such as divorce, or impactful national and global events in the Macrosystem, such as new technological developments, which in turn flow into and have an impact on what happens in the other layers (Bronfenbrenner, "Ecology of the Family” 724). Bronfenbrenner’s conceptualisation presents these systemic layers as inter-connected ecosystems where many seemingly separate factors form a network of important relationships that affect the overall functionality of the environment. Every individual or object has a role that affects the functioning of the whole.

I have linked these systems to a corresponding motivational layer identified as Individual, Empathetic, or Societal using different colours (red, orange, blue and green) to distinguish between the three motivational types as follows:

- Individual motivation is located in the Microsystem. It is where internal influences such as biology, thoughts, desires and emotions might work to directly affect the strength of a person's Thanatophobic and Romantic motivations. Individual motivation sits at the centre because the use of radical life extension ultimately comes down to the individual (as presumed for the sake of this argument).

- The next layer, or Mesosystem, then extends Thanatophobic and Romantic motivations beyond the individual to outside influences close to the individual such as meaningful relationships with family and friends. These relationships can directly impact the individual's motivations if they experience predominant Thanatophobia or Romanticism about another person. It is here that I locate Empathetic Motivation.

- The Exosystem layer once again widens the scope of motivational influence to the individual's wider community and networks of people, services and local events the individual is especially exposed to. It is more localised than the Macrosystem which takes a step further, broadening into larger societal and cultural contexts around the individual, including social class, predominant cultural views, religion and law. The Exosystem, Macrosystem and Chronosystem move beyond Empathetic influencers into the Societal realm. Two shades of blue are used in the diagram to show that while they are both Societal influencers, their scope is different. 
Anna lives in a society where use of radical life extension is lawful and is advertised nationally as a beneficial treatment for those who wish to make the most of life without being impeded by disease or aging. This broader Societal motivation (Macrosystem), is echoed at a community level (Exosytem) where Anna's local health services endorse the use of life extension technology and many other locals have already opted to use it. Radical life extension is thereby viewed as a positive, progressive "healthcare" technology which enables people to live a better quality of life. As a result, Anna views the technology through a Romantic lens due to the pervading Societal influences around her. Though at the more intimate Empathetic motivational layer (Mesosystem), Anna experiences stronger Thanatophobic motivations related to her immediate family who signify her closest relationships. Anna is terrified of losing them, and especially by the thought of the loneliness their permanent absence would cause her. Anna again becomes more Romantically motivated at the Individual layer. She wishes to continue enjoying her life as much as possible, with long term goals she believes will be achieved with the aid of longer life. At the Chronosystem layer, time will continue to pass. The period Anna is living in might also act as an important setting. Various events and experiences may also shift Anna’s Thanatophobic and Romantic motivations across the different motivational layers over time.

\section{5: Empathetic Motivation}

Empathetic motivation in the context of life extension relates to the Thanatophobic and Romantic motivations an individual experience's in relation to the prospect of another person's death. Obvious candidates in this category are loved ones such as partners, friends and family. While it is natural for an individual to experience Thanatophobic and Romantic motivations, I believe it is possible that Empathetic Thanatophobic and Romantic motivations for pursuing and using life extension technology could be just as strong, if not more so, where people care deeply for the well-being and life of another. In these instances:

- The Empathetic Thanatophobic motivation: is most likely to entail a fear of having to live in a world where a loved one is no longer existent (on Earth). This anxiety might be exacerbated by the prospect or direct experience of a loved one having to deal with disease and aging which acts also as a constant reminder of their pending death.

- The Empathetic Romantic motivation: is most likely to entail an individual not wanting a particular person in their life to die because that person makes their own 
life better in some way, for instance, by making the individual happier or as a resource to help them reach a specific goal.

While it would be difficult to compel another person to use radical life extension technology without their consent, the influence of another individual could seriously influence the decision to utilise the technology. This may be via a close relationship and desire to be together or through another person actively convincing someone to extend their life. The relationship between parent and child provides a pertinent example of how Empathetic Thanatophobic and Romantic motivations may play out in this sort of scenario. Imagine Ella, a young woman who desperately wants to prolong her middle-aged mother's life because she does not want to live in a world where her mother no longer exists. In Ella's world radical life extension is already a reality and has recently become available to the general public. Ella and her mother are faced with choosing between using the technology to enjoy a healthy extended life together or rejecting it and facing death sooner. Ella is acutely aware that her mother is likely to pass away first given that she is older. For Ella utilising life extension technology is an obvious choice because she is motivated by having significantly more time with her mother. She subsequently convinces her mother to use the technology for the same reason. In this example Ella is drawing on Empathetic Thanatophobic and Romantic motivations (as well as Individual motivation). She is both terrified of her mother's older age and death but simultaneously finds joy in the prospect of living alongside her mother for an extended period without the prospect of her imminent death.

The above example suggests how the lives of other people, particularly those we care about, can play a crucial role in what motivates an individual to choose a specific action, in this case whether or not to radically extend one's life. While Ella and her mother must surely experience their own Individual Thanatophobic and Romantic motivations, the close familial relationship that tethers them to each other plays a similarly important role in motivating their adoption of life extending technology. It is also possible that neither Ella nor her mother would use the technology if the other refused to do so - in this case study the Empathetic motivation is a more powerful influence than Individual motivation. Here it is very clear that Ella is especially motivated to ensure her mother lives as many healthy years as possible and is determined to bring her mother around to her way of thinking. Of course, where Empathetic motivation is weaker it may be more difficult to convince a close "other" to extend their life. This example is used to illustrate the impact strong Empathetic 
Thanatophobic and Romantic motivations for radical life extension could have on people's perception, treatment and use of the technology if it were to become available.

\section{6: Societal Motivation}

In the bigger picture, Societal motivation may well influence how individuals, as well as groups, view and use radical life extension technology. It is also likely that a person's society and culture will influence how they perceive concepts of life and death and use of life extension, within the restrictions and/or freedoms that the politics, laws and values perpetuated by that society allow. In addition, Societal drivers may determine the characteristics of how a group or population responds to radical life extension opportunities if they are offered. Individuals with knowledge, money and/or power may well influence general consensus. Societal motivation is, therefore, quite ambiguous as it also works within sub-groups with various belief systems who might respond in different ways, albeit within broader societal constraints. Here, the term "society” not only refers to the general populace of a given country, state or city, but the particular groups an individual identifies with, including cultural groups, religious affiliations, ethnicity, socio-economic class and political leanings.

On a societal or group scale, Thanatophobic and Romantic motivations may be harder to determine than those that are Individually or Empathetically inclined, especially where societal influences are subtle and unclear. I contend though that societal factors have the potential to be hugely influential on personal motivation to use life extension technology. Societal motivation also provides an interesting angle from which to discuss the applications part of this thesis, especially in regard to the influence of law and politics. It is also likely to have a significant influence on Individual and Empathetic motivations where specific views are promoted in a society (or societal sub-group) about the nature of life and death, and why it is/isn't acceptable to prolong the human life span. From a Societal perspective Thanatophobic and Romantic motivations are defined as follows:

- Societal Thanatophobic Motivations: A society where life extension technology is legalised and used because death is viewed as dangerous (or at least undesirable) and an unnecessary evil. Death might, for instance, be advertised as such in the media. Similarly, it might be a belief perpetuated by a group of people who share similar beliefs and anxiety about death. 
- Societal Romantic Motivations: A society where life extension technology is legalised and used because it gives people the opportunity to enjoy their life for many more healthy years. The advertising may be similar to that currently used to promote painkillers, where the person's quality of life is amplified because they do not have to experience unnecessary, painful symptoms of illness. Similarly, it might be a sentiment perpetuated by a group of people who share similar beliefs about the usefulness of extending life and having longer to enjoy it.

As stated previously, Societal motivation is perhaps the hardest dimension to quantify because it represents a collective world view with all its nuances, including cultural, political and individual variations and influences within a population of people. In this way, it appears to experience similar philosophical issues to those of moral and cultural relativism in relation to the difficulty of generalising cultural, and group views of different populations of people who may carry a multitude of varied beliefs on a subject (Malik 279).

While Empathetic and Societal motivations are powerful influences on Thanatophobic and Romantic motivations, I focus on Individual motivation as a more appropriate starting point to develop the theoretical foundations for the TRM Spectrum because it is ultimately the individual who will choose whether to support and/or opt to use such a technology.

Nonetheless, it is important to note that environmental characteristics play an influential role in forming the beliefs that underpin the actions that individuals take in relation to adopting life extension technology.

An important aspect of the link between Societal and Individual motivations for radical life extension is how people with the power to create it will implement it. Currently, such a technology is situated in the realms of science fiction, where the power to create it lies with individuals who have the necessary skills, technology, money and knowledge. These people will, of course, be influenced by Societal motivations. However, their Individual (and Empathetic motivations) could also directly impact at the higher societal level because they have the power of creation, of making radical life extension in particular a viable reality. The same applies to those individuals with the influence to implement life extension technology if it were successfully created, such as investors in the current research, politicians and those in the media. Once again, the Individual and Empathetic motivations of these people will 
potentially have direct influence on the treatment of life extension at government levels with respect to legalising radical life extension, which consequently will have a "drip down” effect on a larger population.

As with Empathetic forms of Thanatophobic and Romantic motivation, Societal motivation is unlikely to override individual use of life extension technology to elongate life spans, unless a government enforces its use as part of law related to healthcare. However, this does not mean societal factors do not have the potential to influence an individual's Thanatophobic and Romantic motivations for using life extension technology. For instance, it is feasible that a person influenced by a culture or group that promotes death as something to be deeply feared will have stronger Thanatophobic motivations, which may be consciously or subconsciously generated. Conversely, someone who lives in a society or group where having many healthy years of life is celebrated, is likely to be more Romantically motivated.

At this point it is time to revisit "Ella" who, as in our previous scenario, lives in a world where radical life extension has recently been created. What's more, it is lawful and available to her. However, this time the key factors influencing her motivation to use life extension are Societal. Ella lives in a big city in a country where youth is celebrated and the notion of aging is repugnant. Before life extension technology became available, the norm was to reduce the appearance of aging via means such as plastic surgery and healthy living. This ideal is promoted by the media, advertising companies and medical professionals. Since radical life extension has become a viable option, the concept of aging has become demonised, as has the notion of earlier death through aging and disease. It makes sense, according to the media and many in the population, for people to enjoy a longer, healthier life without the pressure of imminent death in a shorter term. Elderly people still exist although many are forced to live away from the city centre in retirement villages situated in designated areas. Though families do visit their loved ones, overall exposure to aging has become very limited. Ella, who is in her early twenties, is still young and has a fairly impressionable character. Many of her peers are talking of opting for life extension technology in a few years and Ella is thinking of doing the same. The prospect of aging and death scares Ella and she likes the idea of being able to enjoy her life for a longer time without the ailments and disease associated with the aging process. 
In this example, Ella experiences a mix of Thanatophobic and Romantic motivations for postponing aging and death on an Individual level. However, in her case these motivations are hugely impacted by the Societal influences in her immediate environment. In general, the culture of her city through legalising radical life extension and making it easily available seems to have encouraged a pro-life extension stance. It is not surprising that people like Ella and her friends would elect to use life extension technology in the near future. In so doing Ella's personal motivations are reflecting the views being perpetuated by her society and peers. While there may be minority groups operating outside the "mainstream" with alternative views and beliefs about the pros and cons of utilising radical life extension, they will ultimately wield less influence over the general population. Once again, it is ultimately Ella's choice to utilise life extension technology, a decision that will be based on her Individual motivation to do so. In this case Societal motivators play a crucial role by influencing Ella’s beliefs and associated motivations regarding her use of radical life extension.

\section{7: Concluding thoughts: Individual, Empathetic and Societal Motivation}

Individual Thanatophobic and Romantic motivations are central to an individual's decisionmaking about whether to opt in or out of radical life extension. Empathetic and Societal motivations sit alongside as important influencers. In this brief account of how Empathetically and Societally related Thanatophobic and Romantic motivations might manifest themselves in different individuals I have aimed to illustrate the nuanced nature of motivation in relation to life, death and potential radical life extension. It is important to stress that this discussion is speculative in intent with the aim being to show how crucial motivation is to the life extension debate. "Ella" has been used to demonstrate how Empathetic and Societal motivations might apply to the decisions made by individuals contemplating radical life extension use. The scenarios are by no means definitive, but are intended to describe possible, believable instances of how these forms of motivation might play out. I am aware that the Empathetic and Societal parts of the TRM Spectrum are complex and require deeper examination. The intent of this account is to show how the two might interact with Individual motivation and decision making and to act as a starting point for deeper analysis. Empathetic and Societal forms of Thanatophobic and Romantic motivation work to further demonstrate how motivation is not just relevant, but multi-faceted and absolutely crucial to the life extension debate. 


\section{PART 3: APPLICATIONS}

In Part 3, the final section of this work, the TRM Spectrum is applied to two important ethical issues, namely the death penalty versus life imprisonment and the euthanasia and suicide debates. The focus is primarily on Individual and Societal forms of motivation in relation to these known areas of ethical dilemma. I pose that the discourse surrounding these issues are likely to be exacerbated with the introduction of radical life extension. Again I explore and speculate on "what might be", my main aim being to reinforce why I believe it is important to include motivation in the radical life extension debate, to show how it can be applied to "reallife" ethical situations and how understanding its implications will be important for future decision-making on policies affecting humankind. These particular debates have been chosen for analysis because they are contemporary ethical issues that already link into life and death. I am aware the death penalty and life imprisonment, and euthanasia and suicide debates are complex. However, my aim is not to resolve these debates. Instead, the purpose here is to use them to explore the differences between Thanatophobic and Romantic motivations. I propose that individuals and societies for whom the Thanatophobic motivation is dominant will respond to the threats of the death penalty or life imprisonment, and the possibility of euthanasia and suicide differently from those with a predominant Romantic motivation.

\section{1: THE DEATH PENALTY VERSUS LIFE IMPRISONMENT}

The theory of deterrence, which is used as a consequentialist justification for punishment (Magee 231), is used to analyse the role of motivation and radical life extension in relation to the death penalty (or capital punishment) and life imprisonment, both currently and in the future. In so doing I focus on the debate about whether the death penalty or life imprisonment is the most effective deterrent - using the TRM Spectrum as a framework for analysis. I conjecture that an individual with a stronger Thanatophobic motivation is more likely to be deterred by the death penalty while someone who has stronger Romantic motivations might be more deterred by the prospect of life imprisonment. This discussion has two key sections. Firstly, the TRM Spectrum is applied to the contemporary death penalty versus life imprisonment deterrence debate (see 3.12) before moving into the second part, which applies radical life extension to these speculations (see 3.13). Deterrence is woven through both analyses. The Romantic motivation and life imprisonment discussion is also linked to utilitarian arguments such as those of J. S. Mill and Jeremy Bentham, whilst the 
Thanatophobic motivation and capital punishment discussion is guided by van den Haag's “Best Bet” theory.

When referring to the death penalty and life imprisonment as punishment implemented to deter crime, I am referring to pre-meditated, first degree murder which entails “culpable homicide that is intended and is committed in a particularly sadistic, heinous, malicious or inhuman manner” (“Sentencing for Murder”). This is to centralise the discussion by placing the focus upon clear-cut areas of crime associated with the death-penalty and as a foundation to illustrate how the TRM Spectrum may be applied to it, and other ethical issues. I have highlighted the possibilities for the TRM Spectrum to influence viewpoints with potentially positive or negative outcomes for individuals/society in relation to contemporary ethical issues on life and death, and those likely to emerge in the future following the implementation of radical life extension. The TRM Spectrum is shown to be applicable today as well as in a future where radical life extension has been created and implemented.

\subsection{Some context: the death penalty, life imprisonment and notions of deterrence}

The death penalty, or capital punishment, is a form of punishment sanctioned and given by a court of law where the accused is executed by the state for committing a crime ("Death Penalty”). In retentionist countries where the death penalty is still practiced, the nature of the crime must be “of an extreme circumstance” (“Abolitionist and Retentionist Countries”). Many countries are abolitionist, that is, the death penalty has been abolished for all crimes in favour of varying lengths of imprisonment (“Abolitionist and Retentionist Countries”). In these countries, life imprisonment without parole, where the convicted individual's freedom is severely limited due to a designated length of time incarcerated in prison, is the ultimate form of punishment given to those who commit serious crimes. For instance, in New Zealand the penalty for committing first degree murder is a "mandatory penalty of imprisonment for the rest of the offender's natural life” and "a non-parole period of at least 10 years" (“Sentencing for Murder”). What constitutes a "natural lifespan” is not explicitly defined and it is possible for someone convicted for first degree murder to be released within 15-35 years depending on their subsequent behaviour in prison (with parole restrictions). For the purposes of this discussion, life imprisonment in the context of today refers to incarceration for a minimum of 25 years without parole for a person convicted of first-degree murder. The parameters of life imprisonment will take a different tack in the second part of this discussion when radical life extension is also considered. 
Deterrence is a consequentialist normative ethical framework where the morality of an action is determined solely by the results it produces (Magee 231). It is the idea that potential criminals will be deterred from committing a crime when they are aware that the consequences (if caught) will be severe. In other words, enough doubt is created to stop a would-be criminal following through (Kennedy 1). From this perspective punishment is viewed as a preventive measure and as being justified because potential victims are saved as a consequence of a potential criminal being successfully deterred and a crime prevented. Another precedent is where the desired result from disobeying a law is that "we keep ... the [perpetrator] from disobeying the law again” and "keep others from following their example" (Farrell 367). From these perspectives, punishments such as the death penalty and life imprisonment are not viewed as intrinsically good in themselves, but rather the benefit is through the deterrent effects they produce.

There is contention about whether deterrence works as a justification for punishment because it is difficult to judge its effectiveness as a preventative measure due to issues associated with quantifying the numbers of potential criminals who have been deterred by the prospect of the death penalty or life imprisonment (Kennedy 1). For instance, it is unlikely that an individual contemplating first degree murder will admit that they didn't proceed because of the nature of punishment if caught. Another debate relates to whether the death penalty is a greater deterrent than life imprisonment and vice versa. The TRM Spectrum is used in this context to explore "deterrence", how it works as a concept, and which deterrents may be stronger depending on the predominance of a "love" of life or fear of death. The effectiveness of deterrence as a justification for punishment, or the power of the death penalty versus life imprisonment as being a more effective deterrent, are not discussed in this context.

\subsection{2: Applying the motivational Spectrum today}

The TRM Spectrum is applied speculatively to the death penalty versus life imprisonment discourse to illustrate how different individuals potentially relate to one or other of these deterrents. For instance, from the current legal context and related utilitarian perspectives discussed above, it follows that a person with stronger Thanatophobic motivations will be more deterred by the death penalty. This is compared to a person with stronger Romantic motivations who is likely to have a stronger aversion to life imprisonment. However, this 
may not be the case in a future focussed radical life extension context which is also discussed.

The discussion focuses on individual (Individual motivation) and societal perspectives (Societal motivation) related to deterrence. In the case of the individual, a person considering first degree murder, who analyses the potential positive and negative consequences of committing the crime (including the punishment if caught) is likely to make a decision based on what is more likely to benefit/be of least discomfort to them. Ethical egoism, a normative ethical position which advises that an agent ought to pursue their own interests exclusively (Williams 250), is a useful perspective from which to consider why someone might commit murder $^{2}$. The second constitutes a societally focused consequentialist view such as that made by van den Haag, and through use of a utilitarian ethical framework. Hedonistic utilitarianism, for instance, judges the moral "goodness" of an action by its ability to boost net utility through maximising pleasure and minimising pain (Mill, “Utilitarianism” 9-10). From this perspective, the use of a certain punishment would be subsequently judged on its ability to prevent crime by deterring potential offenders and, thereby, increasing the total happiness of that society. The hedonistic utilitarian might subsequently support the death penalty or life imprisonment based on whatever punishment seems to act as a greater deterrent.

Interestingly, the views of hedonistic utilitarian’s, such as J. S. Mill and Jeremy Bentham, appear to be more aligned to a Romantic motivation as both purport life imprisonment (with hard labour) to be a harsher punishment than the death penalty. Mill sums this idea up by stating that "consigning a man to the short pang of rapid death" is better than "immuring him in a living tomb, without its alleviations or rewards, debarred from all pleasant sights and sounds, and cut off from earthly hope” (Mill “Speech in Favour” 268). Mill’s statement shows how a hedonistic utilitarian framework can be used to illustrate a view that life imprisonment is worse than the death penalty. Coincidentally, in the process he aligns

\footnotetext{
${ }^{2}$ I am not looking to assume that every would-be murderer is an ethical egoist - it is very possible many would not be. Nor is it my intent to make a comment about ethical egoism as a moral framework. Though conjecturing about the actions of a murderer might present possible negative implications, it is used here purely as a tool to guide speculation about why someone might be deterred from committing a crime.
} 
himself to a Romantic view ${ }^{3}$. Jeremy Bentham makes what I pose is a similarly Romantic argument with his contention that criminals continually put their lives at risk by participating in "degrading” and unlawful behaviour (Calvert 214), and as such, the prospect of death is less terrifying to them. Bentham suggests instead, that life imprisonment with enforced labour would be a stronger deterrent for criminals because "they will be terrified by a state of passive submission and of laborious confinement, a mode of life in the highest degree repugnant to their natural inclinations” (Bentham 450, i).

Bentham's speculation links into my own view that an individual with stronger Romantic motivations is more likely to be deterred from committing murder by the possibility of life imprisonment than capital punishment because the limits of incarceration will impose more suffering on this type of individual than death. Here I pose that the effect of life imprisonment will be unsatisfactory to the person who places great value on their general autonomy. This kind of autonomy may go beyond any murderous intent and may include more benign actions such as deciding when to have dinner, going for a drive by the seaside or painting a picture. The strength (or weakness) of these deterrent properties may also depend on the type of sentence given, with solitary confinement or hard labour, compounding the effect of general life imprisonment for these individuals, as they place more limitations on the individual's ability for self-determination. Solitary confinement isolates the individual from meaningful social interactions - an especially difficult punishment for someone who enjoys the company of others, and hard labour forces them to consistently perform activities they may not enjoy or find meaning in. In relating this scenario back to the TRM Spectrum, I conjecture that an individual who has stronger Romantic motivations will find the constraints of life imprisonment unappealing and to be avoided. Perhaps akin to a wild animal stuck in a cage. In light of this I propose also that there is alignment between the decision-making and actions of a more Romantically motivated individual in respect to life and death and Bentham's idea that life imprisonment is a greater deterrent than capital punishment.

It could be argued that death also prevents individuals from enjoying their life because they are no longer around to take pleasure in it, and that even an individual with predominant

\footnotetext{
${ }^{3} \mathrm{~J}$. S. Mill did, in fact, support the death penalty on the grounds that it is a greater deterrent than life imprisonment (with hard labour). However, he argued this deterrent effect is the result of a false belief that the death penalty is harsher, when in reality, life imprisonment with hard labour is the more severe punishment (Ten 141).
} 
Romantic motivations may be deterred by capital punishment. I have also speculated that a person with stronger Romantic motivations (in the context of radical life extension) will choose to live longer because they are ultimately more compelled by some aspect of living than a fear of death. Such a person might be motivated by the prospect of fulfilling a goal or by physical pleasures such as food for instance. It is viable, therefore, to also apply this type of motivation, and the TRM Spectrum, to our current, shorter lifespan to explain why life imprisonment may act as a greater deterrent than death as a crime penalty for some individuals.

An interesting implication of this perspective as it applies to Romantic motivation is that in some cases, the death penalty may completely fail as a deterrent and instead have the effect of stimulating an individual to proceed with the heinous act of murder (Ten 148). Herbert Hart captures this view in his hypothesis, that "very large numbers of murderers are very unstable" to a point where the "bare thought of execution, the drama and notoriety of a trial, the gladiatorial element of the murderer fighting for his life, may operate as an attractive force, not as a repulsive one” (88). In this case, the individual's Romantic motivations would also be coming to the fore - to the point where an aspiration such as achieving a certain notoriety and fame, which they believe will be enhanced by the death penalty, completely overrides any deterrent effects related to fear of punishment via execution.

Conversely, strong Thanatophobic motivations have the potential to result in an individual being more strongly deterred by the prospect of death than life imprisonment. The "best bet" consequentialist theory of Ernest van den Haag when applied in this context provides a useful framework for exploring this possibility (147). He uses a best bet theory of deterrence to argue why the death penalty should be retained by posing that it is a stronger deterrent than life detention and thus has a stronger preventative effect. In other words, it is a better bet to have the death penalty than not as "deterring some future murderers" is likely to "spare the lives of some future victims”, resulting in net societal gain (van den Haag, "On Deterrence” 147). As with the related utilitarian arguments outlined above, an individualistic framework such as “ethical egoism” can also be related to van den Haag's wider societal claim. In this case, that the effect of having the death penalty will affect and "save" society from an individual who is contemplating an abhorrent act such as first degree murder. As with the Romantic view, it is likely here that the individual, or potential criminal, will weigh the benefits of committing murder against the negative consequences if caught. According to van 
den Haag, the death penalty is likely to instil more fear than life imprisonment due to a “responsiveness to danger [that] is generally found in human behaviour” (van den Haag, “On Deterrence” 282). On this basis, it is possible to speculate that the more Thanatophobically motivated individual will not be as deterred by the prospect of life imprisonment because "fear of death" is their dominant motivating force. As a result, incarceration is not viewed as such a daunting threat (in some cases it may be pleasanter in prison than outside), especially where they have concluded that the benefits of going ahead with a murder outweigh the confinement of prison.

The use of self-preservation as a defence mechanism also links into the concept of Thanatophobic motivation, where the danger of state-sanctioned execution coupled with fear of death deters an individual from carrying out murder, despite any benefits they believe they might accrue. For instance, it is possible that a potential murderer (either consciously or subconsciously) will perform their own risk analysis to weigh up the benefits and costs likely to result from killing another person. They may eventually conclude that the likely enjoyment or warped sense of meaning they will derive from killing are not worth the risk of death. In this example the deterrent effects of capital punishment can be deemed successful. I predict that in this kind of scenario the Thanatophobic motivation is more predominant because fear of death overrides other factors likely to prompt the desire to kill. In contrast, the prospect of life imprisonment may not deter a more Thanatophobically motivated individual from going ahead with the murder.

In this context, the strongly Thanatophobic individual appears far less likely to be spurred to action by the potentiality of execution and death. This is in comparison to a more Romantically motivated person, who, if Hart's proposal is applied, will be also looking at the consequences in relation to the impact life imprisonment might have on their ongoing quality of life (88). Indeed, it seems to follow that a person who is compelled to murder but deterred from doing so due to a Thanatophobically motivated fear of dying, will view the prospect of capital punishment as having no positive associations and will seek to avoid it.

Furthermore, Bentham when advocating for life imprisonment with hard labour as the better crime deterrent, a view which is more Romantically inclined, also draws on a Thanatophobic motivational viewpoint when explaining that the death penalty appears to be a harsher punishment - and greater deterrent - to the general law-abiding citizen who enjoys a better, 
overall quality of life and thereby has a stronger fear of death (Calvert 219). Bentham is comparing the general law-abiding public with individuals of criminal disposition. In so doing, he suggests that the death penalty ultimately has a stronger deterrent effect on lawabiding citizens but that this impact may be weaker for those of criminal mentality. He rationalises that this is because criminals continually flirt with death due to the type of life they live and thereby accept it as a potential consequence of their actions. Bentham postulates that the criminal portion of a society may be more deterred by the prospect of confinement and hard labour. These views are interesting as they serve to illustrate the potentially different and sometimes overlapping expressions of Thanatophobic and Romantic motivations for choosing life versus death. The result can be very different views, at both Individual and Societal levels, regarding the potential deterrent effects of capital punishment and life imprisonment.

Bentham's idea that capital punishment is a more effective deterrent for law-abiding citizens leads to an interesting speculative question societally. That is, whether a country's use of death-related (capital) or quality-of-life-inhibiting (life imprisonment) punishments as key deterrents is indicative of stronger Societal Thanatophobic or Romantic motivations. At the surface level it makes sense to hypothesise that utilising the death penalty suggests a more Thanatophobically motivated society. However, it is equally feasible that a Thantophobic view may only relate to those instigating capital punishment laws, who are likely to belong to the law abiding general population and who will make decisions on the basis that their perspectives are universal. In taking this approach they appear to be projecting their own Thanatophobic fear of death onto potential murderers who may face the potential of capture and death on a regular basis and as a result be less deterred by the prospect of execution (if caught). Van den Haag's best bet argument ties in here as he promotes taking a gamble in favour of the preventative effects of the death penalty having more beneficial outcomes for society as a whole. Conversely, a country opting for life imprisonment over the death penalty might be judged as more Romantically motivated. In this case, prolonged incarceration may be viewed as a harsher form of punishment than execution because the individual continues living without the same autonomy or choice to pursue the kind of life they aspire to lead generally. Their subsequent appreciation of living is, thereby, likely to be reduced. Bentham argues for life imprisonment (with hard labour) to be the most appropriate punishment for crimes such as murder because it is potentially a stronger deterrent for criminals. He believes that taking a more targeted approach such as this will also result in a higher societal net 
utility, just a van den Haag believes the same result will be achieved through adopting a best bet approach related to the death penalty.

I believe that the TRM Spectrum can be applied to current deterrence debates relating to life imprisonment and the death penalty because of their direct relevance to matters of life and death. In this section I have discussed how a person with stronger Romantic motivations may find the prospect of life imprisonment for committing a serious crime a stronger deterrent than the death penalty, whereas a more Thanatophobically motivated individual may take the opposite position and strongly seek to avoid the death penalty. The theories of Mill, Bentham, Hart and van den Haag have been utilised to consider these perspectives, with ethical egoism utilised as a tool to consider the perspectives of individuals (related to individual motivation) considering a crime such as first degree murder. Although consequentialist ethical frameworks do not directly consider the role of motivation, they do recognise that motivations predictably lead to outcomes. The related theories of deterrence have assisted to show how Thanatophobic and Romantic motivations may inform potential actions linked to serious punishment. For the remainder of this section, deterrence, life imprisonment and the death penalty are considered in relation to a world where radical life extension exists. Whilst individual perspectives are discussed, the focus is societal (related to Societal motivation). The implications of extended life for choosing and implementing punishment for people who can live to 500 years or longer are considered in this context.

\subsection{3: Punishment, motivation and radical life extension}

Radical life extension may also impact on punishment methods, and Individual Romantic and Thanatophobic motivations in relation to crime and punishment. It is possible, also, that the existence of radical life extension technology will require an adjustment to our thinking about the death penalty and life imprisonment as we currently know them. For instance, in this new world variants to the death penalty may include removal of an individual's right to life extension technology and/or altering the life extending effects of the technology. I pose that both scenarios would act as a deterrent for a person predominantly motivated by Thanatophobia. Similarly, the prospect of enforced aging with the possibility of disease, might be an equally significant deterrent for more Romantically motivated individuals. They might view both possibilities as negative experiences to be avoided. This type of punishment may be viewed as a different method of punishment that also impedes (their version of) a fulfilling life. The existence of radical life extension will also necessitate a rethink of the term 
"life imprisonment" as in this new context a "life" term could be for a period of 250 years or more. It is possible that this potentiality will serve to strengthen the deterrent effect of life imprisonment for individuals who are strongly Romantic in their motivation as the limitations imposed by extended confinement of 100 years plus are likely to be extremely problematic for them.

Currently, the death penalty, in countries where it is used, entails the state actively executing criminals via methods that include electrocution, beheading, lethal injection and shooting ('Death Penalty'). However, it is possible that in a post-radical-life-extension world, the death penalty might entail another, arguably "softer” method where those sentenced to death have their right to use life extension technology removed, or (if possible) the life extending effects of such technology reversed so that they are forced to age and die more quickly. I have labelled the death penalty through some form of physical execution as an "active" death penalty, and death by limiting rights to life extension a "passive" death penalty. As alluded to above, this may affect how individuals with stronger Thanatophobic motivations react to the prospect of punishment. In a world where radical life extension is possible, both forms of death penalty are likely to act as effective crime deterrents because both scenarios will force the convicted person to face death sooner than anticipated. In both cases, the individual has lost potentially hundreds of years of added, healthy life, possibly rendering capital punishment to be viewed as a more severe punishment than it currently is.

I conjecture also that for a predominantly Thanatophobic person active execution is likely to act as a stronger deterrent than the passive option. It is a more immediate form of death whereas the passive option has the capacity to revert an individual back to their natural health and life span of, say, 80 years. In this case, they retain a traditional lifespan and have more years to live than active execution even though they are denied the opportunity for extended life. While neither is a desirable option for individuals wishing to delay death, it follows that the option allowing for the longest possible life will be viewed as preferable to immediate death. It is possible also that a passive death penalty, where the right to life extension technology is removed, could be adapted and used as a deterrent for lesser crimes such as theft. It may even come to pass that technology develops to a point where it is possible to reduce and adapt a person's life span relative to the perceived severity of a crime. I suggest that the Thanatophobically motivated person is especially likely to assess the benefits and risks associated with criminal activity against the likelihood of being caught and the nature of 
the punishment, which in the case of a robbery is likely to result in a passive rather than active death penalty. It may also mean that a potential burglar will refrain from committing a crime because of a Thanatophobic motivation that influences them to avoid death for as long as possible through maximising life extension possibilities.

Death might be unappealing to the Romantically motivated individual insofar as it stops them from living the life they aspire to. However, I pose that the stronger a Romantic motivation the more likely it is that the individual will be deterred by life imprisonment - and that this effect will be exacerbated with radical life extension and the prospect of being incarcerated for hundreds of years for a serious crime. This view is supported by Mill and Bentham's utilitarian analyses of life imprisonment as a harsher form of punishment than the death penalty, especially where the duration of incarceration is dramatically increased to adapt to radically enhanced lifespans. Spending hundreds of years in prison without parole instead of, for example, 35 years, is likely to cause the Romantically inclined individual more pain over time, even if the sentence is relative to their radically extended life span. For example, the monotony of a radically extended prison sentence without the prospect of early release may result in a Romantically motivated individual losing the will to live with death becoming a preferred option.

Philosopher Rebecca Roache evaluates how enhancement technology such as life extension might be used to intensify punishment for crime through prison sentences ("More Cyborg Justice”). Roache does not necessarily endorse the possible futuristic torture methods she proposes, which include denying access to certain technologies (such as life extension), and is more "interested in how technology and punishment practices might come to interact in the future, and some of the ways this might happen could be unintentional” ("The Future of Punishment”). She argues that life extension technology has the potential to open possibilities regarding punishment and proposes that the very meaning and length of a life sentence will shift to fit a population who can live for hundreds of years (Roache "Enhanced Punishment"). It seems to follow that, even for a person with stronger Romantic motivations, a 25 year long 'life' sentence in this context is unlikely to deter someone from committing a crime such as murder if the punishment represents only a tiny portion of a life. This is unlikely to be the case though for the same person where the penalty for committing first degree murder is, say, 700 years. 
So, imagine living in a world where radical life extension is available to everyone and utilised by the majority. In this scenario, people live on average for over 700 hundred years and the state has responded by adjusting the maximum life sentence to 550 years without parole. In the early days of life extension technology, it is agreed by those in power that short lengths of incarcerated time, such as 30 years, are not severe enough crime deterrents for individuals with many hundreds more years of life to look forward to. The now extended imprisonment time has meant that those convicted and imprisoned for terrible crimes such as murder spend most, or all, of their extended life incarcerated. In this example, an individual called Fergus is 100 years old but physically has stayed at the age he was when he decided to radically extend his life, which is 30 years. Through standard society-wide testing Fergus has been diagnosed as a psychopath and he has fantasies about murdering another person. In this world his chance of being caught and incarcerated is also extremely high. He is also aware that he potentially has hundreds of years of healthy living available to him and that a sentence for murder will mean he spends most of these years locked away. However, Fergus tends towards the Romantic end of the TRM Spectrum, and while he believes he will find pleasure in murder, he decides the potential sentence is too severe so decides not to proceed with his murder plans. He does not wish to waste the many years he has invested in using life extension by being incarcerated. He would instead prefer to continue with other enjoyable aspects of life that are not punishable by law. Furthermore, he believes enduring hundreds of years in prison will be an unfulfilling and pointless existence.

Fergus's case illustrates how a stronger Romantic motivation and the prospect of life imprisonment might deter a would-be criminal. The pros and cons of committing the crime are weighed up against van den Haag's best bet model, with the potential for life imprisonment presenting as a more severe consequence in this context when combined with radical life extension - even if the life sentence is relative in years to those currently given for serious crimes within a current-day lifespan. In a world of radically enhanced lifespans the prospect of spending hundreds of years in prison for Fergus is hard to imagine and more extreme than anything humankind has so far experienced. Mill's statement about life imprisonment being a stronger deterrent than the death penalty was made long before radical life extension was a technological possibility, but his sentiments remain especially relevant as we navigate this new world where enhancement technologies such as life extension have profound implications for the nature of punishment. It is probable that if the Romantically 
inclined Fergus had committed a serious crime and been captured, he would opt for death over life imprisonment.

However, if Fergus was more Thanatophobically motivated he may still proceed with murder. Changing the primary motivation shifts the focus as Fergus does not view the prospect of being caught and sentenced to hundreds of years in prison a strong enough deterrent, given he will still be fulfilling his strong Thanatophobic motivation to evade death. In this instance a Thanatophobically motivated Fergus is more likely to be deterred from committing first degree murder by the prospect of a punishment such as state sanctioned execution. In this case, there is high likelihood of capture so the potentiality of death must be factored into Fergus's risk/benefit analysis. It is quite possible in this scenario that Fergus will again be deterred from committing a crime, but this time the motivator is different because he is wishing to avoid death via execution. Fergus views this as an unnecessary gamble, because he has invested in radical life extension to delay facing death.

\subsection{Concluding thoughts}

I have given a brief account of deterrence using the lens of Thanatophobic and Romantic motivation in relation to radically extended life. I conjecture that a person with stronger Thanatophobic motivations is likely to be more deterred by the death penalty while a more Romantically motivated person is likely to find life imprisonment a stronger deterrent. The issues of capital punishment and life imprisonment present as an interesting contemporary and future-focussed ethical debate from which to speculate on the role of motivation in relation to individual decision-making processes and as a deterrent. As a debate capital punishment and life imprisonment intrinsically link to life and death, where either could be used as a form of preventative punishment. Radical life extension is also tightly connected to living and dying, and I have taken 
the opportunity here to speculate about how it might change future reactions to, execution of and the deterrence factor of these punishments. In so doing, I have sought to show how the TRM Spectrum can be effectively applied as a framework for analysis to explore the nuanced nature of motivation in relation to radical life extension.

\section{2: EUTHANASIA AND SUICIDE}

The TRM Spectrum with its Thanatophobic and Romantic orientations can also be applied to contemporary and possible future ethical debates (in a life extended world), regarding the moral permissibility of euthanasia and suicide. As with the death penalty, radical life extension could potentially add further complexity to considerations of euthanasia and suicide given that its aim is to eradicate factors such as aging and disease, which currently are counted among key factors influencing individuals' decisions to terminate their life early. It is also possible that actions such as rejecting or opting out of radical life extension (where it is easily accessible to an individual) may become labelled as forms of euthanasia or suicide, because a person is consciously choosing to end their life sooner than would otherwise be the case. This adds another dimension to the current discourse about the moral permissibility or otherwise of euthanasia and suicide.

Arguments about the moral value placed on euthanasia and suicide are discussed in the context of motivation. First (3.22), the TRM Spectrum is applied to current euthanasia and suicide debates. Doerflinger's examination of "sanctity of life" and the "right to autonomy" or self-determination, is drawn on and applied to the Spectrum. In so doing I speculate that an individual with stronger Romantic motivations is likely to place more value on the right to autonomy, whereas someone who is more Thanatophobically motivated may place more value on the sanctity of life. Second, radical life extension is introduced to the euthanasia and suicide debates (3.23). The discussion considers implications for the debates from life extension technology given that disease and aging are no longer issues, with the point being made that sanctity of life and right to autonomy concepts will still apply in a life extended world. John K. Davis's arguments that rejecting or discontinuing radical life extension is a form of "moral suicide" are also evaluated in the context of motivation. Third (3.24), I discuss how Thanatophobically and Romantically motivated societies might potentially view and treat the issue of rejecting or discontinuing radical life extension. Once again, this discussion is purely speculative - I am not looking to make definitive claims about radical life extension, euthanasia and suicide, or to argue either for or against the morality of 
choosing to die sooner. The euthanasia and suicide debates are complex and emotive matters and the parameters of this thesis only allow for me briefly touch upon euthanasia and suicide issues regarding motivation and the TRM Spectrum.

\subsection{1: Some definitions}

Suicide is defined by Michael Cholbi as “intentional self-killing” because "the person believed that the act, or some causal consequence of that act, would make [their] death likely and [they] engaged in the behaviour to intentionally bring about [their] own death” (21). This definition also links to a subset of suicide called assisted suicide, where a medical professional assists a patient with dying if they request it, either by providing a means to it or by recommending and allowing a patient to refuse treatment (Nordqvist 2-3). I have chosen this terminology because it is descriptive and avoids value-laden claims about the morality of suicide (Davis 81 ). This is an important point because I am not looking to argue and justify whether the act of suicide is moral or immoral, but instead to consider how Thanatophobic and Romantic motivations may influence an individual's views on the subject. Euthanasia is the term used to describe the act of intentionally causing the death of a person by taking a positive action, active euthanasia, or allowing them to die via inaction (or "letting die") for the benefit of that person via passive euthanasia (Rachels 77). I also refer to voluntary euthanasia because it involves the agent whose life (or health) is in question consciously choosing death (Nordqvist 2).

\subsection{2: The current euthanasia and suicide debate}

Though distinctions between euthanasia and assisted suicide are made in some arguments and might be implied here by providing separate definitions - the idea that a distinction exists between them can be a point of contention within the debate (Dixon 25). For some, the fact that suicide and voluntary euthanasia, or 'assisted suicide' are both defined by an agent choosing death over life (no matter the circumstances or methods involved) is enough to justify their "sameness" (Doerflinger 16). By introducing an argument based on motivation related to the TRM Spectrum I aim to by-pass issues about the existence of these distinctions and instead, to examine why various individuals have different beliefs or may act differently with respect to the ethics associated with suicide and euthanasia. It is possible, for instance, that a more Romantically motivated person will view euthanasia and suicide as morally permissible if the reasons appeal to the motivation in some aspect, regardless of any societal 
distinctions and laws that might direct them to think otherwise. Conversely, a more Thanatophobically inclined person may view consciously choosing to die as morally impermissible.

The focus here is to hypothesise how Romantic and Thanataphobic motivations may affect moral views about euthanasia and suicide. That a person more motivated by Romantic motivations is likely to view euthanasia (and cases of suicide where euthanasia is not recognised) as morally permissible and a stronger Thanatophobic motivation might lead someone to view both as morally wrong. Doerflinger argues that different ideas about these moral distinctions come down to whether an individual prioritizes the "right to autonomy" or the "sanctity of life" (16). Despite Doerflinger outlining the flaws of an autonomy-based defence of euthanasia, his distinction presents a useful framework for discussing motivation as it applies to the TRM Spectrum. The use of Doerflinger's distinction should not be interpreted as meaning I necessarily support his analysis, nor that I am arguing about the morality of suicide and euthanasia. Rather, this examination uses his ideas to show how Thanatophobic and Romantic motivations may be applied to new and emerging ethical issues related to life extension, and to further emphasise the importance of motivation as a point for consideration within the radical life extension debate.

First, a scenario to aid discussion about the current euthanasia and suicide debates. Imagine Alice, a woman in 2019 who has been fighting cancer a terrible illness for the past 6 months. The initial prognosis was not good, but there was hope she could recover with treatment. However, one month ago she was advised by doctors that the treatment was unsuccessful, that she is terminally ill and there is no hope of recovery. It is projected that she has only a few months to live, but that her life can potentially be extended for a few additional months if she continues her treatment. Alice is in a difficult position. She does not want to die - the thought scares her, and she would like to spend as much time as possible with the people she loves. However, the treatment causes fatigue, pain and vomiting leaving her incapable of doing very much. Although she will die sooner without the medication, opting out of it will vastly (albeit briefly) improve her quality of life - especially her ability to interact with loved ones in those last few months.

In Alice's case, she has the two choices: to remain on treatment or withdraw from it. However, regardless of which option she chooses she will soon die. If she opts for not taking 
medication and thereby shortens her life, she will be choosing a form of passive euthanasia or "letting die”. In countries like New Zealand, this is legal if the patient is suffering and in a terminal condition (Baddock 11). Alternatively, if Alice takes the medication for a few more months she will still experience great suffering given that she is mostly confined to bed, in pain and unable to enjoy the time she has left. In this case, she can choose to live out her remaining days until her death. She can also choose to speed up the inevitable through assisted suicide at a clinic such as Dignitas in Switzerland or (if legal) from a willing physician ("How Dignitas Works”).

This example presents a plausible situation where a person might decide it is more desirable to end their life rather than continue living. Alice's situation is serious, and death is a way to end her suffering. It is also a situation that any one of us may face at any time. It is also feasible to assume that the actions pursued by Alice will be influenced by her underlying beliefs and motivations regarding life and death.

If Alice experiences stronger Thanatophobic motivations, I believe it is unlikely that she would opt out of treatment or choose to end her life sooner via active euthanasia or assisted suicide. In Alice's case fear of death would most likely override any Romantic motivations she also harbours and align to a sanctity of life perspective. This is not to say though that a person motivated by Thanatophobia does not also value autonomy, but only that sanctity of life is a stronger motivation. Sanctity of life also aligns with a Thanatophobic motivation by reinforcing the belief that life over death is more important than autonomy and thereby justifies death avoidance. It seems unlikely that a person strongly motivated by Thanatophobia will choose or support the moral permissibility of euthanasia or suicide - no matter the circumstances involved. To an individual strongly motivated by Thanatophobia, death is abhorrent and to be avoided, whereas life is precious and to be protected. The quality of life argument, such as that relating to Alice's situation, is equally motivated by Thanatophobia, as the moral permissibility of choosing death seems to contradict this possibility. It is thereby likely that a more Thanatophobically motivated society would view the decision to take one's life as morally wrong - perhaps, even, in dire circumstances.

Conversely, a more Romantically motivated Alice may elect to end her life sooner. Extending the debilitating and painful nature of her illness will seem unnecessary if death is imminent 
anyway. Even where continuing treatment prolongs her life for a short time, she does not believe it is enough to justify the additional suffering likely to be experienced. Alice ultimately places greater value on her "quality" of life, which she knows will be lessened due to the pain she is in which leaves her unable to properly enjoy the time she has remaining with loved ones especially. This scenario aims to show how Thanatophobic and Romantic motivations may influence the moral value one places upon the act of ending life or continuing to live it in dismal circumstances and where the morality of doing so is subject to dispute.

Romantic motivation can also be linked to Doerflinger's discussion about the right to autonomy versus the sanctity of life (16-17). I speculate though that a more Romantically inclined individual is likely to place greater value on the right to autonomy or selfdetermination in circumstances where "the individual should be allowed to live without interference rather than a positive right to assistance” (Davis 192). While certain caveats such as causing no harm to others might apply, one should equally be able to live a life of one's own choosing - without impediment from others. For a more Romantically motivated individual, it is likely this value would override the sanctity of life, based on the "conviction that human life is of intrinsic worth" (Doerflinger 16). At the same time, it is likely that individuals with stronger Romantic motivations will still subscribe to a 'sanctity of life' principle, the difference being that the right to autonomy or self-determination may ultimately be more valued in a situation such as Alice's.

It is likely that more Romantically inclined individuals will exercise the freedom to choose death over life in situations where their Romantic motivations for living are no longer being adequately fulfilled. The Romantic approach in this context is aptly summed up by Doerflinger when referring to attorney Robert Risley from the Hemlock society (an advocate for the legalisation of euthanasia) who states that "a life of suffering ... is not the kind of life we cherish” (16). The decision to take one's own life may be accepted as morally acceptable if the reasons for doing so also align with a Romantic motivation. In these circumstances it follows that a more Romantically motivated society may judge certain situations, where one consciously chooses to end their life, as a moral act. Perhaps even to the point where voluntary, active euthanasia is legalised in particular circumstances. 


\subsection{3: Radical life extension enters the picture}

The development of a technology that enables radical life extension, and removes aging and disease as factors that affect the general population, is likely to change the discourse surrounding euthanasia and suicide. Radical life extension offers the potential for humankind to gain significantly more healthy years of living, thereby changing the moral dilemma to one focussed on whether an individual's decision to forgo that time with the knowledge that they will die sooner - is comparable to the current moral debates associated with euthanasia and suicide. I refer to the individual who has access to radical life extension but discontinues or refuses to use it as a "will not” (as John K. Davis terms it) (77). Again, it is possible that motivation will affect both views and acts relating to discontinuing or rejecting radical life extension. In my view a more Romantically motivated person is more likely to refuse or discontinue radical life extension and to believe in moral suicide while those tending towards the strongly Thanatophobic end of the TRM Spectrum are more likely to judge a decision to not utilise or discontinue radical life extension as a form of immoral suicide.

John K. Davis poses the argument that rejecting or opting out of radical life extension is a moral form of suicide. He does not differentiate between euthanasia and suicide preferring instead to examine the morality of choosing death as various forms of suicide. For the sake of continuity, I use the term "suicide" in the same way as Davis to refer to the rejection or discontinuation of radical life extension technology. Davis argues that a "will not" who forgoes radical life extension in any capacity is comparable to a person who discontinues their life support - as in the case of Alice who opts out of life prolonging treatment (83). By connecting his analysis to "letting die" (which he previously justifies as moral), Davis supports his principal claim that rejecting or discontinuing life extension technology is a parallel form of moral suicide (91). However, he evades deeper discussion of how to mediate in a life extension world to ensure that "will nots" are not "force[d] to choose between (a) an extended life they do not want; and (b) committing what they consider to be an immoral kind of suicide" (80). His explanation of why an individual could morally choose an earlier death by rejecting or discontinuing radical life extension technology, aligns, in my opinion, to the more Romantically motivated end of the Spectrum - especially given the greater value assigned to the "right to autonomy" over the sanctity of life. 
The transhumanist Mark Walker also seems to be more Romantically aligned through his speculation that happier people will (on average) be more likely to extend their lives than those who are less happy (591). He justifies moderate to radical life extension from the utilitarian perspective of maximising happiness while also discussing it in terms of "selfselection” (Walker 582). Although Walker does not explicitly label the act of choosing death over extended life as moral suicide, this view appears implicit in his utilitarian argument that relies on "less happy people be[ing] more likely to eliminate themselves as [life extension] recipients” to achieve a positive net happiness societally (591). In addition, suicide and refusing life extension are listed as differentiated methods one might use to self-select out of living, alongside incorrectly following medical prescriptions for radical life extension (Walker 591-593). This argument also seems to support the right to self-determination more than the sanctity of life. If Walker's view is correct, then it follows that utilitarians will be more likely to refuse or opt out of radical life extension, especially where a person is unhappy and no longer wishes to be alive. It is possible also that those with strongly Romantic motivations will follow suit by also self-selecting out of radical life extension on grounds of unhappiness.

Walker though does not discuss 'fear of death' as another powerful motivator relating to the continued use of radical life extension. However, I pose that having a high proportion of unhappy individuals in the population, who also happen to be predominantly Thanatophobic, could mean that they are less likely to 'self-select' out of life extension technology because fear of death will override their negative experiences of living. In this case, the overall net happiness of the group is potentially lower than that predicted by Walker. While it is possible for Thanatophobically motivated individuals to be extremely happy with life, the possibility of having people with predominant Thanatophobic motivations in the general population adds another dimension for consideration by Walker in his utilitarian speculations. Davis also appears to omit the role of motivation, and especially Thanatophobic considerations, from his argument that rejecting or opting out of radical life extension is a moral act of suicide. In so doing, he disregards 'fear of death' as a potential influence on the opposing view that suicide is immoral.

It is possible that those with strong Thanatophobic motivations will instead view a "will not's” refusal to uptake radical life extension (or their discontinuation of it) as an act of immoral suicide. It follows that a 'will not' is unlikely to be strongly Thanatophobically 
motivated as their decision to reject radical life extension in some capacity seems counter to avoiding death for as long as possible. Even though radical life extension presents the potential to extend the life span well beyond known limits I propose that a Thanatophobically motivated individual will still value sanctity of life over the right to autonomy or selfdetermination. Again, this suggests that those with a Thanatophobic motivation will use radical life extension in their quest to extend their life and subsequently delay the prospect of death.

One can argue that the extra years at hand via radical life extension are a "bonus" of sorts. So that once someone has exceeded their natural life span (of, say, 80), the sanctity of life may no longer surpass the right to autonomy for those who might have otherwise placed greater value upon it. The technology, assuming it has been created and implemented for some time, would have moved humanity into a new frame of existence where one's longevity can be manipulated. In these circumstances, even a person strongly motivated by Thanatophobia may come to view the right to autonomy or self-determination as just as or more important - at the very least in cases where technology use is discontinued. In this scenario even those with dominant Thanatophobic motivations might align more closely with the arguments of Davis and Walker than previously. Though, I imagine there will still be those who continue to privilege sanctity of life and who will subsequently view the act of rejecting or discontinuing radical life extension technology as immoral.

This view also links to the idea that individuals who privilege life and fear death will tend to view rejecting extra years of life as wasteful, akin to the way we currently grieve the death of a child as opposed to that of an 87 year old who has lived a long life. Although both are sad and painful for their kin, a child's death is more likely to be viewed as a tragedy due to all the missed years of life (Kass, "The Case for Mortality” 181). Phrases such as they "went too soon" are likely to be uttered with little consolation in respect to the child's death, whereas some comfort may be found in an elderly person who had “a good innings” by experiencing a long life (Kass, “The Case for Mortality” 181). The sadness caused by a child's passing is magnified through one's knowledge of all the unlived years that have been lost/gone to waste in the event of early death. There is potential I believe for views of this nature to transfer to the radical life extension context where perceptions of old age will cease to exist and non-use and 
mis-use of the technology will be viewed as wasteful, irrespective of how many extra years a person has lived. I suggest that individuals with predominant Thanatophobic motivations who also adhere more to the sanctity of life are the group most likely to view a “will not's” decision to reject or discontinue radical life extension as an immoral and wasteful act.

The moral value placed on a "will not" rejecting or discontinuing radical life extension is also likely to have societal level implications. While individuals with prominent Thanatophobic motivations are likely to encourage the view that non-uptake of radical life extension is an immoral act, those who are strongly Romantic in their motivations are likely to encourage the opposing viewpoint that it is acceptable and moral.

It is possible that as with the life imprisonment/death penalty discussion, the stances taken by different societies (for instance countries, states and cities) in response to radical life extension uptake will be strongly influenced by the motivational predispositions of the decision-making majority. Therefore, it follows that a more Thanatophobically motivated society, which believes also in the sanctity of life, is likely to enforce radical life extension use, with penalties for those who resist. Conversely, those societies with a more strongly Romantic predisposition, and who also subscribe to a self-determination view, may legalise, and even assist, individuals who wish to reject or discontinue life enhancing technologies. They will in effect be legalising euthanasia and condoning suicide. While this is another purely speculative discussion, I believe the points made further demonstrate how the TRM Spectrum can usefully be utilised as a framework to understand the nuanced nature of human motivation and potential responses to the opportunities presented by life extension technology if successfully developed.

\subsection{4: Moral or immoral suicide at a societal level}

Thanatophobic and Romantic motivations may also affect the use of radical life extension for medical purposes and its use as either an ordinary or extraordinary treatment, which may or may not be universally accessible. Here, “ordinary measure” refers to any treatment where there is reasonable hope of the patient benefitting, or where the benefits outweigh the negatives (Kuhse 74). Conversely, “extraordinary measures” denote any treatment with little or no benefit to the patient, and where any benefits do not outweigh the negatives (Kuhse 74; Rachels 77). 
Countries such as New Zealand could be viewed as having predominant Societal Thanatophobic motivations due to the value these countries place on the sanctity of life - at least from a legislative point of view where euthanasia and assisted suicide are currently illegal $^{4}$ (Braddock 10). Similarly, The American Medical Association (AMA) states that "the intentional termination of the life of one human being by another ... is contrary to that for which the medical profession stands and is contrary to the policy of the AMA.” (Rachels 77). This policy refers to a central value, that euthanasia and physician-assisted suicide are “fundamentally incompatible with the physician’s role as healer” (American Medical Association ch.5, 8). Medical professionals provide treatment to protect and prolong life, they do not assist in the ending of it ("Euthanasia”). The sanctity of life, at least in the eyes of the law, is more important than the patient's right to autonomously decide to end their life. However, the AMA does make an allowance for the cessation of extraordinary treatment used to prolong the life of the body: "when there is irrefutable evidence that biological death is imminent it is the decision of the patient and/or his immediate family” (Rachels 77). This scenario is akin to the example given in 3.32, where a terminally ill patient chooses to discontinue life support. It also presents as a slightly more flexible stance on the sanctity of life, where this type of case might be allowed as morally permissible by American society as a whole.

I conjecture here that a society more motivated by Thanatophobia will view radical life extension as a form of "ordinary" treatment. For this to occur radical life extension technology will need to be easily accessible and sophisticated enough to become accepted as a common form of "lifesaving" therapy. If disease is eradicated in the process of using the technology, it will be a bonus. As an analogy, life enhancing technology used to enhance the health and wellbeing of a population may well be likened to current forms of ordinary treatment to preserve health and extend life such as minor operations or the use of an inhaler by an asthmatic person. To view radical life extension as a form of ordinary treatment aligns with the perspective that to reject or decline its use is to perform an immoral act of suicide. The patient stands to benefit (health-wise) from its use and the benefits are considered to

\footnotetext{
${ }^{4}$ This might change if New Zealand's “End of Life Choice Bill” submission, which looks to legalise doctor assisted suicide, is passed ("End of Life Choice Bill"). The Bill has been a subject of contention within in the country, including opposition from the New Zealand Medical Association (Braddock 1).
} 
outweigh any associated negative consequences. However, the ultimate benefit in a more Thanatophobically motivated society is that by prolonging life death is delayed.

A stronger Romantic motivation might, conversely, influence another society to view radical life extension as a type of extraordinary treatment. Davis appears to pick up this line of thinking in his argument that rejecting or forgoing radical life extension is a form of moral suicide, equivalent to declining life support. It is possible that the AMA term "extraordinary treatment”, which I pose is more aligned to a Thanatophobic motivational disposition, will be interpreted differently in a Romantically oriented society. Radical life extension in this context may be viewed as an extra, or a bonus, which perhaps becomes available after a prescribed period of life, the intention then being to allow people the time and health to enjoy their life in the ways they see fit, for as long as they choose. For those who have easy access to the technology and wish to utilise it, radical life extension may present as ordinary treatment because they simultaneously experience the benefits of the good health promoted via extended life while also subscribing to strong Romantic motivations to continue living life to the full. However, unlike a more Thanatophobically motivated society, these 'bonus' years may also be forfeited, perhaps in a similar way to Walker's speculative theory of 'selfselection', if an individual decides they have had enough and no longer wish to continue living. From this perspective, prolonging life has more negative than positive outcomes because the individual no longer wants to be alive.

In addition, a post-radical life extension society with dominant Thanatophobic motivations is likely to view rejecting or discontinuing the technology as an immoral form of suicide, particularly where high value is placed on the sanctity of life. It is consequently possible that any governmental or official decision-making body will make rejecting the technology unlawful (if available to an individual) while also not allowing for, or assisting in, decisions to discontinue radical life extension. The technology may conceivably require an expert in radical life extension to terminate its effects, which is likely to limit access to this form of intervention and to be particularly troubling for those who wish to avail themselves of it. Furthermore, the physical signs of the aging process will be a giveaway for anyone who unlawfully undertakes this course of action. In these circumstances the active option, of immediate death via lethal injection or an equivalent method, is likely to be viewed as more extreme and immoral than the formerly discussed passive alternative. This is potentially because a stronger Thanatophobic motivation might influence one to view a slower death, 
even with aging, as more desirable than instantaneous death. While I believe it unlikely that a strongly Thanatophobically motivated society will condone any form of harm resulting in death, the quicker death option is likely to be viewed as extreme given that avoiding death is their prime motivator. Here greater value is placed on life than having autonomy over how that life plays out. In addition, those with predominant Thanatophobic motivations within this society are unlikely in the first place to opt for these methods. Conversely, people who are more Romantically motivated and value the right to autonomy are likely find their views conflict with these overarching societal values and may be forced to find other means to end their life if warranted.

A country such as Switzerland may be perceived as comparatively more Romantically motivated, given its emphasis on autonomy and allowances for assisted suicide (Hurst and Mauron page.). These interventions currently occur within a highly regulated environment, where people seeking this option are required to prove they are in a terminal, incurable position through providing medical evidence to this effect (Hurst and Mauron page). However, with the eradication of aging and disease via life extension technology, this circumstance is likely to become almost redundant. The recent Australian court ruling to allow 104-year-old David Goodall, who had maintained good physical and cognitive abilities (Bever), to end his life because he no longer enjoyed it could be an indication of what is in the future for more Romantically motivated societies.

As previously mentioned, a more Romantically motivated society may find ways to allow and support the rejection or cessation of radical life extension. At the very least, I believe this course of action will be viewed by them as a moral act and the choice to utilise technology for these purposes will be left to the individual without interference from a governing body. Another possibility is that the state or governing body will provide assistive interventions to end the dependence of their populace, where this is desired, on life extending technology . Take for example a radically life extended 560 year old (with the capacity to live another few hundred years) who decides that they do not wish to live out the additional years on offer via radical life extension because they have already fulfilled all their goals. Although they have taken up hobbies and tried to find other interests, they have failed to find anything that sparks their passion. The past 100 years have, therefore, felt meaningless and boring, with the result that they prefer to end their life now (Kass, "In Defense of Mortality”, 182). In these circumstances a Romantically motivated society is likely to regulate for this eventuality, 
which may include provisions for a minimum age requirement and psychiatric evaluations over a period of time to ensure that the individual is certain about their decision.

Once again, there is likely to be a choice available of either a passive option of "letting die", where the effects of radical life extension are stopped to allow aging to resume, or an active option where the person is killed immediately using lethal injection or a similar method designed to quickly end a life. I speculate here that a more Romantically motivated individual will prefer instantaneous death to a slower process, which includes disintegration through ageing, because they are no longer gaining satisfaction from their life. Arguably, they are ready to die. An instant death, therefore, is likely to present as preferable. It is possible also, that "will nots" who do not want to radically extend their life, will use the technology moderately to avoid the experience of aging and/or disease. This approach could present as an appealing middle ground, especially initially, to Romantically oriented governing bodies who in response may be positively disposed towards assisting "will nots" at a societal level in the form of structures to assure that individuals are acting autonomously, are of sound mind and do wish to die. In so doing instantaneous self-determined death would potentially become legalised, subject to pre-approved conditions. Potentially also with assistance akin to Switzerland's Dignitas clinics, which might become more widely available in this scenario.

\subsection{5: Concluding Thoughts}

The purpose of this discussion about euthanasia and suicide has been to to illustrate how motivation can inform decision-making. Furthermore, the contemporary ethical debates related to euthanasia and suicide using the TRM Spectrum as an analysis tool allow us to foreground future issues in a tangible way. As with the death penalty versus life imprisonment debate, euthanasia and suicide are directly associated with matters of life and death - although here it is related to the choice of living or dying rather than to punishment for crime. It is again possible that radical life extension will influence the values that apply, especially regarding potential "will-nots” who reject or opt out of radical life extension. I have conjectured that a more Thanatophobically motivated person (or society) will view 'opting out' as “immoral suicide” due to the greater value placed on the sanctity of life. Conversely, those with a stronger Romantic motivation are more likely to align with the view that to 'opt out' is not "immoral” but rather a form of moral suicide due to the greater value they place upon the right to autonomy, or self-determination. By applying the TRM Spectrum to associated ethical issues like euthanasia and suicide, the complexity of motivation is 
highlighted. Thanatophobia and Romanticism can both motivate towards the same outcome the decision to use radical life extension. However, applications such as this help to show the different, nuanced ways in which motivation may affect the very way we potentially use or abuse the technology. 


\section{CONCLUSION}

I have argued why motivation is a crucial element to consider in relation to the development and potential use of radical life extension technology - though it has surprisingly emerged as largely absent from the current life extension debate. This analysis has thereby had three key purposes: 1) to argue why motivation is an important element of radical life extension and worthy of deeper examination; 2) to encourage introspection related to one's motivations for developing or using radical life extension technology; and 3) to illustrate how different motivations might impact the way radical life extension technology is used. It has not been my intention to offer arguments about the moral "rightness" or "wrongness” of developing and utilising radical life extension as I believe motivation wraps around these ethical debates and can be used as a tool for analysis from multiple perspectives. Understanding more about the motivational factors that can influence our decisions and actions is crucial to establishing a more nuanced approach to the ethics of radical life extension.

To aid my analysis, I have created and employed the TRM Spectrum as a framework to capture why some people may be highly motivated to develop life extension technology, and why and how others may be motivated to use it if it is successfully created. Fear of death and appreciation, or "love” of life are complex motivators, and are not necessarily mutually exclusive. In this way, the Spectrum acts to show how people are potentially motivated by varying, changing degrees of Thanatophobic and Romantic motivations throughout their lives. I have also intentionally designed Thanatophobia and Romanticism as broad terms for what I believe are the two key motivating factors, to better encapsulate the variety of reasons one might have for choosing radical life extension. The nuances of the motivational Spectrum is further extended with the introduction of Empathetic and Societal motivation. Though Individual motivation is especially focused upon to centralise discussion, these latter forms of motivation are included to acknowledge their contributing role to decision-making in relation to life extension. Outlining how Empathetic and Societal and Thanatophobic and Romantic motivations work together to potentially influence Individual motivation adds a further layer of complexity to the radical life extension discussion.

This is not to say I am arguing the Thanatophobic and Romantic Motivational Spectrum is the "end word” when exploring motivational factors related to radical life extension. Nevertheless, I do believe that both terms are broad enough to cover many of the factors 
related to it. This belief has been tested when applying the TRM Spectrum to the contemporary and future-focussed ethical debates related to the death penalty, life imprisonment, euthanasia and suicide, which simultaneously and intrinsically link to the concepts of life, death and radical life extension. The technology, if successfully created and implemented, is likely to directly influence the way these issues are viewed and the policies and practices which are adopted.

Radical life extension has the potential to grant us greater control over death than ever before. Its impact will be far-reaching and will include how we relate to life and death at a very fundamental level. With these unknowns at hand - and possibly around the corner - we must start thinking deeply about our motivations for adopting a radically longer life. The reason why we use or pursue any life enhancing technology can have a significant impact on its overall treatment. This thesis has made a case for why motivation, as conceptualised in the TRM Spectrum, should become an important addition to the life extension discourse. It is my hope that this analysis will encourage further thinking on the subject. If humanity wishes to fast forward into a future where radically extended life is possible, we need to be clear about our reasons for doing so, individually and as a society. 


\section{WORKS CITED}

“Abolitionist and Retentionist Countries as of July 2018”. Amnesty International. 2018 www.amnesty.org/download/Documents/ACT5066652017ENGLISH.pdf. Accessed 8 Sept. 2018

A Reimagined Research Strategy for Aging. SENS Research Foundation, 2019, www.sens.org/ourresearch/intro-to-sens-research/. Accessed 4 April 2018.

Agar, Nicholas. Humanity's End: Why We Should Reject Radical Enhancement. MIT Press, 2010.

---."Thoughts about our species’ future: themes from Humanity’s End: Why We Should Reject Radical Enhancement." Journal of Evolution and Technology 21 (2010): 23-31.

---. Agar, Nicholas. Truly human enhancement: a philosophical defense of limits. MIT Press, 2013.

American Medical Association. Code of Medical Ethics. "Chapter 5: Opinions on Caring for Patients at the End of the Life. June 2019. https://www.ama-assn.org/system/files/2019-06/code-ofmedical-ethics-chapter-5.pdf. Accessed 8 June 2019.

Bargh, John A. "Our unconscious mind." Scientific American310.1 (2014): 30-37.

Becker, Ernest. The Denial of Death. The Free Press, 1973.

Bentham, Jeremy. "The Work of Jeremy Bentham, Vol. II, ed." John Bowring. London, New York: Russell and Russell (1962).

Bever, Lindsay. This Australian Scientist Just Turned 104. Now He’s Flying to Switzerland to Die. The Washington Post, May 3 2018,www.washingtonpost.com/news/to-yourhealth/wp/2018/04/30/a-scientist-just-turned-104-his-birthday-wish-is-todie/?noredirect=on\&utm_term=.8a4e560ca489. Accessed 2 Jul. 2018.

Bostrom, Nick. "The fable of the dragon tyrant." Journal of Medical Ethics 31.5 (2005): 273-277.

Braddock, Dr Kate. New Zealand Medical Association. End of Life Bill. Feb 2018. https://www.swbc.org.nz/wp-content/uploads/2018/02/NZMA-Submission-on-End-of-LifeChoice-Bill-FINAL.pdf. Accessed 12 Apr. 2019.

“How Dignitis Works”. Dignitas, 2019, www.dignitas.ch/index.php?option=com_content\&view=article\&id=23\&Itemid=84\&lang=e n. Accessed 21 Jan. 2019.

Bronfenbrenner, Urie. "Ecological models of human development." Readings on the development of children 2.1 (1994): 37-43.

---."Ecology of the family as a context for human development: Research perspectives."

Developmental psychology 22.6 (1986): 723.

---. "Toward an experimental ecology of human development." American psychologist 32.7 (1977): 513.

Bronfenbrenner, Urie. "Toward an experimental ecology of human development." American psychologist 32.7 (1977): 513-531. 
Calvert, Brian. "Bentham and the death penalty." Dialogue: Canadian Philosophical Review/Revue canadienne de philosophie 45.2 (2006): 211-231.

Cholbi, Michael. Suicide: The philosophical dimensions. Broadview Press, 2011.

Davis, John K. The New Methuselahs: The Ethics of Radical Life Extension. Massachusetts Institute of Technology, 2018.

“Death Penalty”. Amnesty International. 2018. https://www.amnesty.org/en/what-we-do/deathpenalty/. Accessed 8 Sept. 2018.

De Beauvoir, Simone. Memoirs of a Dutiful Daughter. Tr. by James Kirkup. Deutsch/Penguin, 1959.

De Grey, Aubrey and Rae, Michael. Ending Aging: The Rejuvenation Breakthroughs that Could Reverse Human Aging in Our Lifetime. St Martins Press, 2007.

Dixon, Nicholas. "On the Difference between Physician-Assisted Suicide and Active Euthanasia DIXON - 1998 - Hastings Center Report - Wiley Online Library.” Hastings Center Report, John Wiley \& Sons, Ltd, 23 Mar. 2012, onlinelibrary.wiley.com/doi/epdf/10.2307/3528229. PDF file.

Doerflinger, Richard. "Assisted suicide: Pro-choice or anti-life?" The Hastings Center Report 19.1 (1989): 16-19.

“End of Life Choice Bill.” New Zealand Parliament, www.parliament.nz/en/pb/bills-and-laws/billsproposed-laws/document/BILL_74307/end-of-life-choice-bill. Accessed 12 Apr. 2019.

“Euthanasia.” American Medical Association, 1995-2019, www.ama.assn.org/deliveringcare/ethics/euthanasia. Accessed 8 Jan. 2019.

“Executive Team.” SENS Research Foundation, 2019, www.sens.org/about-us/leadership/executive. Accessed 4 Apr. 2018.

Forgas, Joseph P., et al., eds. Social motivation: Conscious and unconscious processes. Vol. 5. Cambridge University Press, 2005.

Fukuyama, Francis. Our Posthuman Future: Consequences of the Biotechnology Revolution. Farrar, Straus and Giroux, 2002.

Greenberg, Jeff, and Jamie Arndt. "Terror management theory." Handbook of theories of social psychology 1 (2011): 398-415.

Hall, G. Stanley. “Thanatophobia and Immortality.” The American Journal of Psychology, vol. 26, no. 4, Oct. 1915, p. 550. JSTOR, doi:10.2307/1412814.

Hart, Herbert Lionel Adolphus. Punishment and responsibility: Essays in the philosophy of law. Oxford University Press, 2008.

Hefferon, Kate, and Ilona Boniwell. Positive psychology: Theory, research and applications. McGraw-Hill Education (UK), 2011.

Heidegger, Martin. Being and Time. $1^{\text {st }}$ ed., Translated by John Macquarrie and Edward Robinson. Blackwell Publishers Ltd, 1962 (2001). Div. 2, ch.1, sec. 46-53.

Huxley, Aldous. "Brave New World. 1932." London: Vintage (1998).

Jones, Barry. Dictionary of World Biography. ANU Press, 2018. 
Kass, Leon. Life, Liberty and the Defense of Dignity: The Challenge of Bioethics. Encounter Books, 2002.

---. "L'Chaim and its limits: why not immortality?" First Things (2001): 17-24.

---. "The Case for Mortality." The American Scholar (1983): 173-191.

Keen, Sam. Foreward. The Denial of Death by Ernest Becker, The Free Press, 1973.

Kennedy, David M. Deterrence and crime prevention: Reconsidering the prospect of sanction. Routledge, 2012.

Kuhse, Helga. "Debate: extraordinary means and the sanctity of life." Journal of medical ethics 7.2 (1981): 74-82.

Kurzweil, Ray. "The Singularity Is Near: When Humans Transcend Biology. Viking." New york (2005).

Magee, Bryan. The story of philosophy. Penguin Random House, 2016.

Malik, Kenan. The Quest for a Moral Compass: A Global History of Ethics. Atlantic Books Ltd., 2014.

Mill, John Stuart. "Speech in Favour of Capital Punishment (1868).” Applied Ethics, by Peter Singer, Oxford University Press, 1986, pp. 97-104.

---. Utilitarianism. Longmans, Green and Company, 1895.

Nordqvist, Christian. "Euthanasia and assisted suicide." Medical News Today (2016).

Nordqvist, Christian. "Euthanasia and Assisted Suicide: What Are They and What Do They Mean?” Medical News Today, MediLexicon International, 17 Dec. 2018, https://www.medicalnewstoday.com/articles/182951.php. Accessed 3 Mar. 2019.

Pyszczynski, Thomas. "Understanding the opposition to long-term extension of the human lifespan - Thomas Pyszczynski.” YouTube, uploaded by Sens Foundation, February 19 2014, www.youtube.com/watch?v=biNF_a5QbwE. Accessed 6 Apr. 2018.

Pyszczynski, Tom, Jeff Greenberg, and Sheldon Solomon. "Why do we need what we need? A terror management perspective on the roots of human social motivation." Psychological inquiry 8.1 (1997): 1-20.

Rachels, James. "Active and passive euthanasia." Bioethics: An Introduction to the History, Methods, and Practice (1975): 77-82.

Recher, Harry F., and Denis A. Saunders. "Tribute to David William Goodall DSc, AM: advocate and ecologist par excellence (4 April 1914 to 10 May 2018)." Pacific Conservation Biology 25.1 (2019): v-vii.

Roache, Rebecca. “Enhanced punishment: can technology make life sentences longer?”. University of Oxford, 2 August 2013 (edited 26 March 2014), blog.practicalethics.ox.ac.uk/2013/08/enhanced-punishment-can-technology-make-lifesentences-longer/. Accessed 15 Sept. 2018.

---. “More Cyborg Justice: André Interviews Rebecca Roache about the Future of Punishment”. Practical Ethics, University of Oxford, 25 Apr. 2014, http://blog.practicalethics.ox.ac.uk/2014/04/more-cyborg-justice-andre-interviews-me-aboutthe-future-of-punishment/. Accessed 15 Sept. 2018. 
---. “The Future of Punishment: A Clarification”. Rebecca Roache, Weebly, 25 Mar. 2014, https://rebeccaroache.weebly.com/blog/the-future-of-punishment-a-clarification. Accessed 15 Sept. 2018

Robine, Jean-Marie, and Michel Allard. "The oldest human." Science 279.5358 (1998): 1831-1831.

Seligman, Martin E. P., and Mihaly Csikszentmihalyi. "Positive Psychology: An Introduction.” American Psychologist, vol. 55, no. 1, Jan. 2000, pp. 5-14. APA PsycNET, doi:10.1037/0003066x.55.1.5.

"Sentencing for Murder”, New Zealand Law Commission. NZLII. http://www.nzlii.org/nz/other/nzlc/pp/PP41/PP41-8_html. Accessed 2 Feb. 2019

Singer, Peter. "Research into aging: should it be guided by the interests of present individuals, future individuals, or the species." Life span extension: Consequences and open questions (1991): 132-145.

Sirgy, M. Joseph, and Jiyun Wu. “The Pleasant Life, the Engaged Life, and the Meaningful Life: What about the Balanced Life?” Journal of Happiness Studies, vol. 10, no. 2, 2007, pp. 183196. SpringerLink, doi:10.1007/s10902-007-9074-1.

Solomon, Sheldon, Jeff Greenberg, and Thomas A. Pyszczynski. The Worm at the Core: On the Role of Death in Life. Random House Incorporated, 2015.

Sutton, Mike. "The Concept of Death in Philosophy and Experience." (2016). https://philarchive.org/rec/SUTTCO-8, 1-6, Microsoft Word File.

Ten, C. L. “Mill’s Defense of Capital Punishment”. Criminal Justice Ethics, vol. 36, no. 2, 2017, pp. 141-151., doi: 10.1080/0731129x.2017.1358919

Thanato-, comb.form. Def.1. OED: Oxford English Dictionary, Oxford University Press, 2019, www.oed.com/view/Entry/200125?redirectedFrom=thanatophobia\&. Accessed 10 Mar. 2018.

Turner, Bryan S. Can We Live Forever?: A Sociological and Moral Inquiry. Anthem Press, 2009.

Turner, Leigh. "Life extension research: health, illness, and death." Health Care Analysis 12.2 (2004): 117-129.

Van Den Haag, Ernest. "On deterrence and the death penalty." Ethics 78.4 (1968): 280-288.

Van den Haag, Ernest. "The Ultimate Punishment: A Defense." Harvard Law Review 99.7 (1986): 1662-1669.

Vélez-Agosto, Nicole M., et al. "Bronfenbrenner’s bioecological theory revision: Moving culture from the macro into the micro." Perspectives on Psychological Science 12.5 (2017): 900-910.

Walker, Mark. "Superlongevity and Utilitarianism." Australasian Journal of Philosophy 85.4 (2007): 581-595.

Williams, Bernard. “Chapter 15: Egoism and Altruism.” Problems of the Self: Philosophical Papers 1956-1972, Cambridge University Press, 1973, pp. 250-265.

Wong, Paul T. P., and Adrian Tomer. "Beyond Terror and Denial: The Positive Psychology of Death Acceptance.” Death Studies, vol. 35, no. 2, 10 Feb. 2011, pp. 99-106. Taylor and Francis Online, doi:10.1080/07481187.2011.535377. 
Wong, Paul TP. "What is Existential Positive Psychology?" International Journal of Existential Psychology and Psychotherapy 3.1 (2011). 